\title{
Diagnosis and management of iatrogenic endoscopic perforations: European Society of Gastrointestinal Endoscopy (ESGE) Position Statement
}

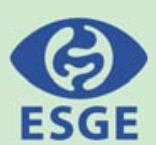

Authors

Institutions
Gregorios A. Paspatis ${ }^{1}$, Jean-Marc Dumonceau² ${ }^{2}$ Marc Barthet ${ }^{3}$, Søren Meisner ${ }^{4}$, Alessandro Repici ${ }^{5}$, Brian P. Saunders ${ }^{6}$, Antonios Vezakis ${ }^{7}$, Jean Michel Gonzalez ${ }^{3}$, Stine Ydegaard Turino ${ }^{4}$, Zacharias P. Tsiamoulos ${ }^{6}$, Paul Fockens ${ }^{8}$, Cesare Hassan ${ }^{9}$

Institutions are listed at the end of article.
Bibliography

Dol http://dx.doi.org/

10.1055/s-0034-1377531

Published online: 21.7 .2014

Endoscopy 2014; 46: 693-711

(c) Georg Thieme Verlag KG

Stuttgart · New York

ISSN 0013-726X

\section{Corresponding author}

Gregorios A. Paspatis, MD

Gastroenterology Department

Benizelion General Hospital

Heraklion, Crete

Greece 71409

Fax: +30-2810-368018

gpaspatis@gmail.com

This Position Paper is an official statement of the European Society of Gastrointestinal Endoscopy (ESGE). It addresses the diagnosis and management of iatrogenic perforation occurring during diagnostic or therapeutic digestive endoscopic procedures.

\section{Main recommendations}

1 ESGE recommends that each center implements a written policy regarding the management of iatrogenic perforation, including the definition of procedures that carry a high risk of this complication. This policy should be shared with the radiologists and surgeons at each center.

2 In the case of an endoscopically identified perforation, ESGE recommends that the endoscopist reports: its size and location with a picture; endoscopic treatment that might have been possible; whether carbon dioxide or air was used for insufflation; and the standard report information.

3 ESGE recommends that symptoms or signs suggestive of iatrogenic perforation after an endoscopic procedure should be carefully evaluated and documented, possibly with a computed tomography (CT) scan, in order to prevent any diagnostic delay.
4 ESGE recommends that endoscopic closure should be considered depending on the type of perforation, its size, and the endoscopist expertise available at the center. A switch to carbon dioxide insufflation, the diversion of luminal content, and decompression of tension pneumoperitoneum or tension pneumothorax should also be done.

5 After closure of an iatrogenic perforation using an endoscopic method, ESGE recommends that further management should be based on the estimated success of the endoscopic closure and on the general clinical condition of the patient. In the case of no or failed endoscopic closure of the iatrogenic perforation, and in patients whose clinical condition is deteriorating, hospitalization and surgical consultation are recommended.
RCT randomized controlled trial

SEMS self-expandable metal stent

SEPS self-expandable plastic stent

TTS through-the-scope

\section{Introduction \\ $\nabla$}

latrogenic perforation of the gastrointestinal tract related to diagnostic or therapeutic endoscopy is a rare but severe adverse event, associated with significant morbidity and mortality. The absolute number of iatrogenic perforations is likely to increase [1], because of the widespread implementation of endoscopic screening programs and the expansion of the indications for therapeutic 
endoscopy. Improvements in the endoscopic and surgical treatments of iatrogenic perforations might substantially reduce the associated morbidity and mortality, underlining the importance of correct diagnosis and management of these events [2]. Because of the lack of high quality studies, mainly due to the rarity of these adverse events, clinical/radiological/surgical strategies to deal with iatrogenic perforation are unclear. The clinical outcome of the patients depends on the timing and efficacy of such interventions, so that the lack of well-defined strategies may by itself be responsible for a suboptimal outcome.

In this Position Statement, ESGE aimed to define the main risk factors for iatrogenic perforations as well as clear diagnostic and therapeutic algorithms for their management. ESGE issues these recommendations as a position statement rather than a guideline because of the scarcity of high quality studies.

\section{Methods}

$\nabla$

ESGE commissioned this Position Statement. The development process included meetings and online discussions among members of the committee during December 2012 and November 2013. Subgroups were formed, each in charge of a series of clearly defined key questions. The guideline committee chairs (G.P., C.H., J.M.D.) worked with the subgroup leaders (A.R., M.B., J.M.D., S.M., B.S.) to identify pertinent search terms that included: iatrogenic perforations, endoscopy, clips, surgery, as well as terms pertinent to specific key questions. For ease of literature searching, key questions were formulated using PICO (participants, interventions, comparators, outcomes) methodology [3].

Searches were performed on Medline (via Pubmed) and the Cochrane Central Register of Controlled Trials up to October 2013. Articles were first selected by title; their relevance was then assessed by reviewing full-text articles, and publications with content that was considered irrelevant were excluded. Because of the lack of well-designed studies on the diagnosis and management of iatrogenic perforations, quality of evidence and strength of recommendations were not formally graded [4].

Each subgroup developed draft proposals that were presented to the entire group for general discussion during a meeting held in December 2013 (Frankfurt, Germany). Further details on the methodology of ESGE guidelines have been reported elsewhere [4].

In April 2014, a draft prepared by G.P. was sent to all group members. After agreement on a final version, the manuscript was reviewed by two experts selected by the ESGE Governing Board and it was sent to all ESGE individual members and societies for comments/endorsement. It was then submitted to the journal Endoscopy for publication.

This Position Paper was issued in 2014 and will be considered for update in 2018. Any interim updates will be noted on the ESGE website: http://www.esge.com/esge-guidelines.html.

\section{Recommendations and statements \\ $\nabla$}

Evidence statements and recommendations are stated in italics. For ease of clinical use general recommendations and statements are given first followed by in the recommendations and statements for specific organs. A summary of the recommendations and statements is presented in $\bullet$ Table $\mathbf{1}$.

\section{General policy \\ $\nabla$}

ESGE recommends that each center implements a written policy regarding the management of iatrogenic perforations, including the definition of procedures that carry a high risk of this complication. This policy should be shared with the radiologists and surgeons at each center.

Iatrogenic perforations are associated with a high risk of morbidity and mortality. Such risks can probably be reduced by using an evidence-based algorithm for diagnosis and management. As outlined below, awareness of the risk factors, prompt availability of adequate radiological imaging, as well as clinical, endoscopic and surgical competence may be expected to substantially improve patient outcome. Because of its complexity, this condition is better managed by a multidisciplinary approach, including endoscopic, radiological, and surgical competences that need to be readily available.

In particular, the existence of a clear policy may prevent a situation where iatrogenic perforation has catastrophic consequences because of the non-availability of appropriate clinical, radiological, or surgical expertise. Although iatrogenic perforation is relatively rare, it is not a completely unpredictable adverse event. Some procedures appear to carry a relatively high risk, allowing a simple stratification between low risk and high risk procedures. It is reasonable to assume that implementation of policies before and not after the introduction of the procedure would by itself minimize the morbidity and mortality risk associated with endoscopic perforation. For instance, the simple awareness that a particular procedure is at high risk of esophageal perforation should indicate that the procedure should not be performed unless a surgeon with adequate thoracic competence is available. Similarly, lack of training with or non-availability of dedicated endoscopic devices would unnecessarily expose patients with iatrogenic perforations to surgical risks. Moreover, failure to use computed tomography (CT) instead of plain film radiography to detect subtle perforations may result in diagnostic delay. Thus the management team for iatrogenic perforations seems to resemble that of stroke and gastrointestinal bleeding units, where prompt collaboration and availability of required competences has led to better clinical outcomes $[5,6]$. The availability of dedicated protocols may also represent a structural quality indicator for the health system.

\section{Reporting \\ $\nabla$}

In the case of an endoscopically identified perforation, ESGE recommends that the endoscopist reports: its size and location with a picture; endoscopic treatment that might have been possible; whether carbon dioxide or air was used for insufflation; and the standard report information.

Acute iatrogenic perforation during endoscopy is defined as the presence of gas or luminal contents outside the gastrointestinal tract [7]. The timing of diagnosis is critical for management and patient outcome [8-10]. Endoscopy shows a high sensitivity and specificity for diagnosis of iatrogenic perforation [11]. Concerns that air insufflation associated with endoscopy may worsen the extraluminal contamination associated with perforation have not been conclusively demonstrated in any recent study; therefore such concerns should not prevent adequate reporting of the perforation characteristics and should not prevent possible treatment. In the case of an endoscopically recognized perforation, a 
Table 1 latrogenic endoscopic perforations: summary of recommendations from the European Society of Gastrointestinal Endoscopy (ESGE).

- ESGE recommends that each center implements a written policy regarding the management of iatrogenic perforation, including the definition of procedures that carry a high risk of this complication. This policy should be shared with the radiologists and surgeons at each center.

- In the case of an endoscopically identified perforation, ESGE recommends that the endoscopist reports: its size and location with a picture; endoscopic treatment that might have been possible; whether carbon dioxide or air was used for insufflation; and the standard report information.

- ESGE recommends that symptoms or signs suggestive of iatrogenic perforation after an endoscopic procedure should be carefully evaluated and documented, possibly with a computed tomography (CT) scan, in order to prevent any diagnostic delay.

- ESGE recommends that endoscopic closure should be considered depending on the type of perforation, its size, and the endoscopist expertise available at the center. A switch to carbon dioxide insufflation, the diversion of luminal content, and decompression of tension pneumoperitoneum or tension pneumothorax should also be done.

- After closure of an iatrogenic perforation using an endoscopic method, ESGE recommends that further management should be based on the estimated success of the endoscopic closure and on the general clinical condition of the patient. In the case of no or failed endoscopic closure of the iatrogenic perforation, and in patients whose clinical condition is deteriorating, hospitalization and surgical consultation are recommended.

- ESGE suggests that endoscopic dilations, mucosal resection/submucosal dissection, and foreign body removal should be considered to carry an increased risk of esophageal or gastric perforation.

- ESGE recommends endoscopic treatment for esophageal and gastric perforations using clips or other devices, especially for perforations $<10 \mathrm{~mm}$. Temporary stent placement is particularly useful for large esophageal perforations. For gastric perforation $>10 \mathrm{~mm}$, use of over-the-scope clips (OTSCS) or omental patching, or the combined technique using an endoloop and through-the-scope (TTS) clips are recommended. If such treatment is unfeasible or fails, or in the case of clinical deterioration, hospitalization and surgical consultation are recommended. General principles of management also include nil-by-mouth regimen, with intravenous administration of proton pump inhibitors, broad spectrum antibiotics, fluids, and on-demand pain medication.

- The most common causes of perforations related to endoscopic retrograde cholangiopancreatography (ERCP) are sphincterotomy (56\%) and guidewire manipulation (23\%). ESGE suggests that precut, Billroth II gastrectomy, and biliary stricture dilation should be considered to entail increased risk for biliopancreatic perforation.

- The majority of ERCP-related ductal or periampullary duodenal perforations can be managed nonsurgically. The indications for surgery are a major contrast medium leak, severe sepsis despite nonsurgical management, severe peritonitis, and fluid collections or unsolved problems (e. g., retained hardware) that cannot be solved by nonsurgical means. After careful patient selection, nonsurgical management is successful in more than $90 \%$ of patients.

- For the nonsurgical management of ERCP-related ductal or periampullary duodenal perforation, ESGE recommends antibiotics and nasogastric or nasoduodenal aspiration in all patients; stenting of the perforated duct (or of the biliary duct in the case of periampullary perforation) on a case-bycase basis; and total parenteral nutrition in undernourished patients as well as in patients in whom adequate enteral feeding is presumed not to be feasible for $\geq 7$ days. Cross-sectional imaging should be performed during follow-up and, if a liquid collection is disclosed, percutaneous drainage should be considered. The efficacy of TTS clips in closing periampullary perforations is unknown.

- ESGE suggests that altered anatomy, stricture dilation in Crohn's disease, dilation of gastrojejunal stricture after gastric bypass, endoscopic submucosal dissection (ESD) and, in patients with altered anatomy, double-balloon enteroscopy (DBE) are risk factors for duodenal and small-bowel perforation.
- In type I (i. e. nonperivaterian) duodenal perforations, ESGE recommends endoscopic treatment if the iatrogenic perforations is recognized immediately and, in the case of failure of endoscopic treatment, immediate surgery. If the duodenal perforation is diagnosed later $(>12 \mathrm{~h}$ ), management should be surgical in the case of contrast medium extravasation or of persistent large fluid collection at CTscan, or if the patient's condition deteriorates. If the patient is in good condition without extravasation of contrast medium or persistent large fluid collection seen at CT, the patient should be treated conservatively without intervention. For iatrogenic perforations in the small bowel, the ESGE recommends surgical treatment although some iatrogenic perforations caused by dilation of a stricture at a gastrojejunal anastomosis (GJA) may be treated conservatively.

- ESGE recommends that complex endoscopic mucosal resection (EMR), endoscopic submucosal dissection (ESD), and balloon dilation procedures should be considered to carry increased risk of colorectal perforation. Older age, co-morbidity, inflammatory colonic disease, use of hot biopsy forceps, and endoscopist inexperience are other significant risk factors for iatrogenic perforations at colonoscopy.

- ESGE recommends the use of TTS endoclips for small holes and OTSCS for larger ones. Adequate colon preparation is an important factor when contemplating endoscopic treatment of iatrogenic perforations. All patients treated conservatively should be watched closely by a multidisciplinary team in the immediate post-procedure period. Immediate surgical repair is required in the case of larger perforations or where endoscopic closure has failed or where the patient's clinical condition is deteriorating.

comprehensive and clear written report is critical in driving further management. Thus, incomplete reporting-that may be dictated by the fear of future medicolegal litigation - may expose patients to needless diagnostic or therapeutic delays and cause a suboptimal outcome. A clear report stating that the endoscopic therapy applied to the iatrogenic perforation was effective is likely to represent by itself an indication not to proceed to surgery, whilst a report of failure to close a perforation may warn against any delay in surgical treatment. Awareness about the use of carbon dioxide or air may be critical in the interpretation of endoscopic and clinical findings. In order to simplify surgical access, an accurate description of the size and location of the iatrogenic perforations is also required [12]. The availability of photographic documentation of the perforated area may be useful for the multidisciplinary approach, and also for legal considerations.

ESGE recommends that symptoms or signs suggestive of iatrogenic perforation after an endoscopic procedure should be carefully evaluated and documented, possibly with a computed tomography (CT) scan, in order to prevent any diagnostic delay.

Iatrogenic perforations are not always recognized at endoscopy. For instance, in a study spanning 10 years of practice, only $68 \%$ of colonoscopy-related perforations were diagnosed within 24 hours [13], so that a high level of suspicion for perforation is required when evaluating some post-endoscopy symptoms, especially following procedures with a high risk of perforation. Early diagnosis has been shown to substantially impact the post-perforation outcome, mainly because it allows potential surgical intervention in an uncontaminated setting [14]. An early search for iatrogenic perforations should be prompted by unusual abdominal pain with distension, chest pain, subcutaneous emphysema, or shortness of breath, while iatrogenic perforation at a later stage is associated with more severe symptoms or signs, such as systemic inflammatory response, hypotension, and mental confusion.

Chest and abdominal plain film radiography are considered to be suboptimal compared with CT scanning [15]. The advantages of CT over plain film radiography include the ability to detect small 
amounts of gas in the peritoneum, retroperitoneum or mediastinum, as well as the ability to use luminal contrast to evaluate the efficacy of endoscopic perforation closure.

$\mathrm{CT}$ also has a higher sensitivity than plain film radiography for the detection of extraluminal liquids or small pneumothorax. In detail, CT imaging has the higher accuracy for showing small quantities of free air, fluid collections, or empyema in the mediastinum and/or pleural or peritoneal cavity and it provides better definition of adjacent structures [15]. The ingestion of watersoluble contrast prior to $\mathrm{CT}$ adds accuracy because it may display the site of extravasation [16].

After endoscopic resection, small air bubbles caused by transmural injection may be seen in the absence of actual iatrogenic perforation $[9,17]$. Pneumomediastinum or pneumoperitoneum, without any endoscopic evidence of perforation, can be shown by CT scans in $31 \%-63 \%$ of all gastroesophageal endoscopic submucosal dissection (ESD) procedures $[18,19]$. Thus, radiologic findings should always be interpreted in conjunction with endoscopic and clinical findings.

\section{Treatment \\ $\nabla$}

ESGE recommends that endoscopic closure should be considered depending on the type of the perforation, its size, and the endoscopist expertise available at the center. A switch to carbon dioxide endoscopic insufflation, the diversion of luminal content, and decompression of tension pneumoperitoneum or tension pneumothorax should also be done.

Randomized controlled studies performed in animal models have shown that the endoscopic closure of iatrogenic perforations is feasible, prevents peritonitis and, compared with surgery, limits adhesions $[20,21]$. Thus, it may be decisive in influencing patient outcome, and need for surgery following iatrogenic perforation. Different devices may be applied, mainly according to the size of the iatrogenic perforation. It is unlikely, however, that holes larger than $3 \mathrm{~cm}$ may be endoscopically treated.

Clean contents of the gastrointestinal lumen and adequate expertise of the endoscopist are prerequisites for successful endoscopic closure of iatrogenic perforations. Nasogastric or nasoduodenal tubes should be used for diversion of gastrointestinal fluids, as appropriate. Although early involvement of the surgeon is advisable, his/her presence is not required for the endoscopic treatment of the iatrogenic perforation, as the endoscopist usually has more experience than the surgeon in endoscopic closure of iatrogenic perforations.

In the case of hemodynamic or breathing disorders caused by air under tension, decompression should be done as an emergency measure [22]. In a Japanese series, half of the patients underwent successful peritoneal decompression during the procedure [23] (Video e1, available online).

Carbon dioxide insufflation is generally recommended during long gastrointestinal endoscopy procedures in patients without severe underlying pulmonary disease [24]. Switching from air to carbon dioxide for insufflation in the case of unexpected iatrogenic perforation may prevent tension-pneumothorax, tensionpneumomediastinum, or tension-pneumopericardium, and the abdominal compartment syndrome, although supporting data are lacking $[24,25]$.

After closure of an iatrogenic perforation using an endoscopic method, ESGE recommends that further management should be based on the estimated success of the endoscopic closure and on the general clinical condition of the patient. In the case of no or failed endoscopic closure of the iatrogenic perforation, and in patients whose clinical condition is deteriorating, hospitalization and surgical consultation are recommended.

In the case of iatrogenic perforation, hospitalization is nearly always required. However, selected patients with asymptomatic iatrogenic perforation treated endoscopically may be discharged, but close follow-up should be considered [26].

All patients admitted to the hospital should be treated with general supportive measures including intravenous antibiotics, nothing by mouth, and close multidisciplinary follow-up.Parenteral nutrition is recommended in undernourished patients or in well-nourished patients with expected non-alimentation for $\geq 7$ days [27]. Close clinical multidisciplinary monitoring (by endoscopists, surgeons, and intensive care physicians) is required, with special attention to signs of sepsis and peritonitis that could lead to urgent surgical management.

Early surgery is generally to be preferred in patients with large perforations, generalized peritonitis, ongoing sepsis, deteriorating clinical condition, after failure of percutaneous drainage, or with an active leak or with presence of a definite amount of free fluid detected at CT that cannot be drained percutaneously.

Iatrogenic perforations that are diagnosed late (particularly duodenal iatrogenic perforations) also require surgical drainage, which carries a high morbidity and mortality $[8,9,14,28,29]$.

\section{Gastroesophageal perforations}

\section{High risk gastroesophageal procedures}

ESGE suggests that endoscopic dilations, mucosal resection/submucosal dissection and foreign body removal should be considered to carry an increased risk of esophageal or gastric perforation.

\section{Esophagus: high risk procedures}

Most esophageal perforations are associated with therapeutic endoscopic maneuvers, and occur in the thoracic part of the esophagus $[30,31]$. Iatrogenic perforation is the most frequently reported major complication of esophageal dilation [30]. The risk is low $(0.09 \%-2.2 \%)$ for simple ring or peptic strictures [30], and much higher for strictures that are complex (angulated, multiple, or long), caustic, or radiation-induced [32,33]. The perforation rate in pneumatic dilation for achalasia has been reported to range broadly between $0.4 \%$ and $14 \%$, and it seems to be lower if a $30-\mathrm{mm}$ balloon is used first with an interval, stepwise approach [34,35].

Endoscopic resections have also been associated with esophageal perforations: retrospective series on endoscopic mucosal resection (EMR) (mostly for Barrett's esophagus) have reported perforation rates between $0 \%$ and $3 \%[36,37]$.

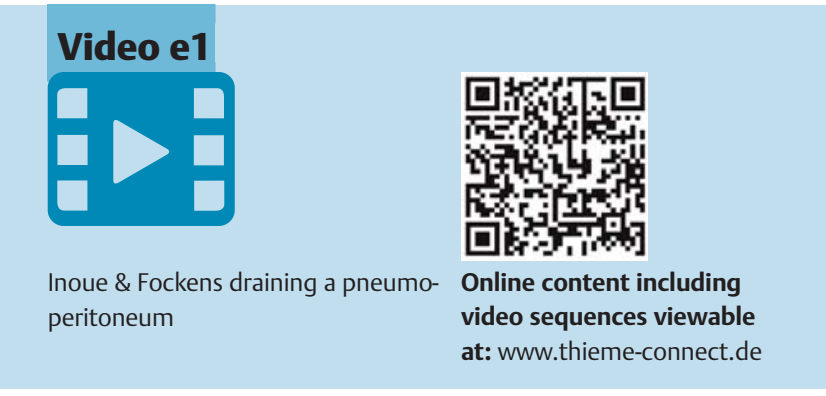


Comparably low rates of perforation (2.4\%) have been reported by Japanese authors for endoscopic submucosal dissection (ESD) of squamous cell cancer [38]; these have been confirmed by limited European series [39,40].

Finally, regarding foreign bodies, a large, irregular, or sharp shape, impaction in the esophagus for a very long duration, and a history of repeated intentional foreign body ingestion are all risk factors for esophageal perforation [41]. Passage of transesophageal echocardiography probes has also been associated with iatrogenic perforation.

\section{Stomach: high risk procedures}

Iatrogenic gastric perforations are most often related to therapeutic procedures, including: gastroenteric anastomosis dilation (2\%) [42]; overdistension during argon plasma coagulation or cryotherapy $(<0.5 \%)$; standard snare polypectomy; EMR $(0.5 \%)$ and, more frequently, ESD [43]. Additional risk factors during EMR and ESD are: the presence of an ulcer or unhealthy (e.g. irradiated) tissues [44], age $>80$ years, large tumor size, location of the lesion in the thinner upper region, and long duration of the resection $[43,45,46]$.

\section{Treatment of gastroesophageal perforations}

ESGE recommends endoscopic treatment for esophageal and gastric perforations using clips or other devices, especially for perforations $\leq 10 \mathrm{~mm}$. Temporary stent placement is particularly useful for large esophageal perforations. For gastric perforations $>10 \mathrm{~mm}$, use of over-the-scope clips (OTSCS) or omental patching, or the combined technique using an endoloop and through-the-scope (TTS) clips are recommended. If such treatment is unfeasible or fails, or in the case of clinical deterioration, hospitalization and surgical consultation are recommended. General principles of management also include nil-by-mouth regimen, with intravenous administration of proton pump inhibitors, broad spectrum antibiotics, fluids, and on-demand pain medication.

\section{Esophagus: treatment}

Some of the prerequisites or conditions that favor successful general and endoscopic management include: early recognition and treatment ( $<24$ hours) of the perforation; small size of the defect ( $<1 \mathrm{~cm}$ for through-the-scope [TTS] clips, $<2 \mathrm{~cm}$ for OTSCs); a clean esophagus with little or no passage of its content into the mediastinum; lack of patient co-morbidities, and absence of clinical instability following perforation; treatment by an experienced interventional endoscopist; and management by an experienced multidisciplinary team $[9,16,47-49]$. A perforation located in the cervical esophagus has more potential for successful conservative management because of anatomical factors; the fascial planes of the neck reduce the risk of contamination of the mediastinal organs $[16,48]$. Generally, if the patient is unstable after perforation then surgery is indicated. If recognition of the perforation is late ( $>24$ hours) and radiology shows free perforation and/or important fluid collections in the mediastinum/ pleural cavity, or if the patient has co-morbidities, then surgery is indicated $[9,48,50]$. Similarly, surgery must be advocated when there is no local endoscopic expertise in advanced therapeutic maneuvers or when there is evidence of leak persistence after previous endoscopic treatment.

The main endoscopic management options for esophageal perforations include closure with clips, and diversion of enteral con- tents with stents, or endoscopic vacuum therapy ( $\bullet$ Table 2 ). In a systematic review, TTS clips were reported as a successful method (in all cases) for closing esophageal perforations ranging from 3 to $25 \mathrm{~mm}$ (median size $10 \mathrm{~mm}$ ) [51]. A limitation of TTS clips is their restricted ability to close large defects because of their limited wingspan; moreover TTS clips cannot approximate perforation edges when there is scarring or inflammation in cases of late treatment or previous unsuccessful attempts [52]. Larger esophageal perforations may be treated using the OTSC. In a recent European multicenter cohort study, enrolling 36 consecutive cases of iatrogenic perforation, [2] all of 5 esophageal perforations were successfully closed endoscopically, using a combination of OTSC and TTS clips $(n=3)$ or OTSCs only $(n=2)$ to close the defect. Temporary stent placement has also been proposed for the treatment of mid and lower esophageal perforations [53]. Table 2 summarizes the outcome after treatment, with partially covered self-expandable metal stents (PC-SEMSs), or fully covered self-expandable metal stents (FC-SEMSs), as well as self-expandable plastic stents (SEPSs). In perforations spanning the gastroesophageal junction, the use of PC-SEMS is preferred because of the migration risk of FC-SEMS, particularly in the absence of stricture. Stents are deemed particularly useful for treatment of large esophageal perforations $[54,55]$, and in cases of malignancyassociated perforation where they also contribute to relief of dysphagia [56].

Vacuum therapy enhances the formation of granulation tissue and healing by secondary intention, by reducing bacterial contamination, secretions, and edema. Endoscopic vacuum therapy is achieved using a sponge attached to the tip of a nasogastric tube that is placed on the site of perforation under endoscopic guidance $[57,58]$.

Oral intake must be interrupted for an adequate period (i.e., at least 5 days). The patient should be treated with intravenous broad spectrum antibiotics, proton pump inhibitors, and fluid reconstitution. On-demand pain medication should be administered intravenously. Partial diversion of the luminal content may be achieved by insertion of a nasogastric tube, which, when possible, should be placed under endoscopic vision and left with continuous controlled suction $[9,59]$. Placement of a nasogastric tube in a patient with a small perforation that has been correctly sealed is not recommended because of the risk of dislodging the clips. Nasogastric tubes have not been used after the placement of self-expandable metal stents (SEMSs) for esophageal fistula sealing [60].

If radiologic investigations show fluid collection and/or the formation of empyema in the mediastinum and/or pleural cavity, percutaneous drainage is indicated.

Mortality after esophageal perforation is high despite any definitive surgical or conservative strategy. Analysis of 75 studies showed a pooled mortality of $11.9 \%$ (95\% confidence interval [95\%CI] 9.7-14.3; 75 studies with 2971 patients) with a mean hospital stay of 32.9 days (95\%CI $16.9-48.9 ; 28$ studies with 1233 patients) [61].

\section{Stomach: treatment}

When the perforation is diagnosed during or within 12 hours of endoscopy, endoscopic closure has been associated with good patient outcome. If the perforation is asymptomatic and recognized later than 12 hours, the approach may be conservative. In a recent retrospective series [62], 38 patients with perforations were initially treated nonoperatively. The majority showed neither clinical evidence of peritonitis nor required interventions 
Table 2 Efficacy of endoscopic treatment for esophageal iatrogenic perforation.

\begin{tabular}{|c|c|c|c|c|c|c|c|}
\hline First author, year & Study design & Type of treatment & Patients, n & $\begin{array}{l}\text { Technical } \\
\text { success, \% }\end{array}$ & $\begin{array}{l}\text { Clinical } \\
\text { success, \% }\end{array}$ & $\begin{array}{l}\text { Complica- } \\
\text { tions, \% }\end{array}$ & Mortality, \% \\
\hline Eroglu, 2009 [78] & Retrospective & SEMS & 4 & 100 & n.a. & 0 & 0 \\
\hline Freeman, 2009 [79] & Prospective & SEPS & 19 & 100 & 89 & 24 & 0 \\
\hline Salminen, 2009 [80] & Retrospective & SEMS & 8 & 100 & 75 & 25 & 37.5 \\
\hline Amrani, 2009 [81] & Prospective & SEMS & 2 & 100 & 100 & 0 & 0 \\
\hline Leers, 2009 [82] & Prospective & SEMS & 9 & 100 & n.a. & n.a. & $<6$ \\
\hline Kiernan, 2010 [83] & Retrospective & SEMS & 8 & 100 & 75 & n.a. & 12 \\
\hline $\begin{array}{l}\text { Vallböhmer, } 2010 \\
\text { [59] }\end{array}$ & Retrospective & SEMS & 12 & 100 & n.a. & 8 & 0 \\
\hline Van Heel, 2010 [55] & Prospective & SEMS/SEPS & 31 & 100 & 97 & 33 & 21 \\
\hline Schimdt, 2010 [84] & Retrospective & SEMS + endoclip & $21+1$ & 100 & n.a. & n.a. & $<13.3$ \\
\hline Swinnen, 2011 [85] & Retrospective & SEMS & 23 & 100 & n.a. & n.a. & n.a. \\
\hline Làzàr, 2011 [86] & Retrospective & Endoclip & 1 & 100 & 100 & 0 & 0 \\
\hline Dai, 2011 [87] & Prospective & SEPS & 5 & n.a. & 83 & n.a. & n.a. \\
\hline D'Cunha, 2011 [88] & Retrospective & SEMS/SEPS & 15 & 95 & 60 & 13 & 6.7 \\
\hline Baron, 2012 [71] & Retrospective & Novel OTSC & 1 & 100 & 100 & 0 & 0 \\
\hline Lin, 2014 [89] & Retrospective & Mesh-covered stents & 9 & 100 & n.a. & 4 & 55.6 \\
\hline Biancari, 2013 [90] & Retrospective & $\begin{array}{l}\text { Unspecified stents + } \\
\text { endoclips }\end{array}$ & $11+1$ & 100 & n.a. & 25 & 46 \\
\hline Wilson, 2013 [91] & Retrospective & SEMS & 7 & 100 & n.a. & n.a. & n.a. \\
\hline Wahed, 2013 [92] & Retrospective & Unspecified stent & 2 & 100 & 0 & n.a. & 100 \\
\hline Voermans, 2012 [2] & $\begin{array}{l}\text { Prospective, } \\
\text { multicenter }\end{array}$ & OTSC & 5 & 100 & 100 & 0 & 0 \\
\hline $\begin{array}{l}\text { Schweigert, } 2013 \\
\text { [93] }\end{array}$ & Retrospective & SEMS/SEPS & 13 & 100 & 15 & 85 & 15 \\
\hline Sato, 2013 [94] & Retrospective & Endoclip & 1 & 100 & 100 & 0 & 0 \\
\hline Heits, 2014 [95] & Prospective & Vacuum therapy & 10 & 100 & 90 & 20 & 10 \\
\hline Hadj, 2012 [96] & Retrospective & OTSC+SEMS & 1 & 100 & 100 & 0 & 0 \\
\hline Biancari, 2014 [97] & Retrospective & SEMS/endoclips & 67 & 100 & 15 & 34 & 19.4 \\
\hline
\end{tabular}

n.a., not available; OTSC, over-the-scope clip; SEMS, self-expandable metal stent; SEPS, self-expandable plastic stent

beyond conservative management and only $18 \%$ required surgery. The only factors associated with failure of nonoperative treatment were free fluid or contrast extravasation seen on CT scan $(75 \%$ vs. $23 \%, P<.005$, and $33 \%$ vs. $0 \%, P=.047]$, respectively). The morbidity in operated patients after initial nonoperative management was equivalent to that observed in patients who underwent initial operative management ( $63 \%$ vs. $61 \%$; $P$ value not significant); however mortality was greater in those who underwent operative management after failed endoscopic treatment than in those who underwent initial operative management ( $43 \%$ vs $21 \%, P=0.09$ ).

In the case of late recognition of perforation, conservative management may be attempted after a CT scan evaluation that confirms the absence of peritoneal effusion and with close monitoring for signs of sepsis. Late recognition of gastric perforations with septic symptoms is generally associated with peritonitis due to leak of intra-abdominal fluid. These patients generally require surgical management ( $\bullet$ Fig. $\mathbf{1}$ ).

Endoscopic treatment for small gastric defects $(<10 \mathrm{~mm})$ In the case of perforations smaller than $10 \mathrm{~mm}$ (the opening width of TTS clips) with a linear shape, endoscopic clipping is an acceptable method and should be attempted [63]. Sometimes, the clip placement may be difficult because of the location of the perforation. In such cases, the recently described band ligation technique [64] can be an interesting alternative. In the literature there are only a few papers on acute endoscopic iatrogenic perforations of the stomach, with to date a total of 145 patients having been treated with endoclips [65]. In detail, eight studies on acute iatrogenic perforations after EMR or ESD procedures have been reported and TTS clips were used in all these studies. Pooling these studies, the overall success rate using TTS clips was $>99 \%(\bullet$ Table 3$)$.

Endoscopic treatment for large gastric defects ( $>10 \mathrm{~mm}$ ) TTS clips alone are not recommended for perforations $>10 \mathrm{~mm}$. In the case of perforations measuring $10-30 \mathrm{~mm}$, the OTSC system has been the most evaluated technique and it has demonstrated its efficacy in clinical studies for the management of postoperative leaks or fistulas [66-69]. Regarding acute gastric perforations, four relevant papers have highlighted the efficacy of OTSC (- Table 4) $[2,70-72]$ with a total success rate of more than $95 \%$ (22 patients). All of these experimental and clinical studies recommend OTSCs for the management of gastric defects between 10 and $30 \mathrm{~mm}$ in diameter, with or without the use of grasping devices to place them. However, perforations $>20 \mathrm{~mm}$ are challenging to manage endoscopically, requiring experience and the availability of surgery in case of failure. If the OTSC technique is unavailable, the combined technique using TTS clips plus endoloop can be recommended [73-75]. When the omentum is visible through the defect, the omental patch technique may be recommended $[63,76]$, especially if the defect is very large ( $\bullet$ Table 5). The use of the new suturing devices must be restricted to expert centers and/or the setting of clinical trials.

Finally, the nonsurgical treatment of gastric perforations may include the use of removable fully covered self-expandable metal stents (FC-SEMSs) or self-expandable plastic stents (SEPSs); these stents are indicated for perforations caused by dilation of a gas- 


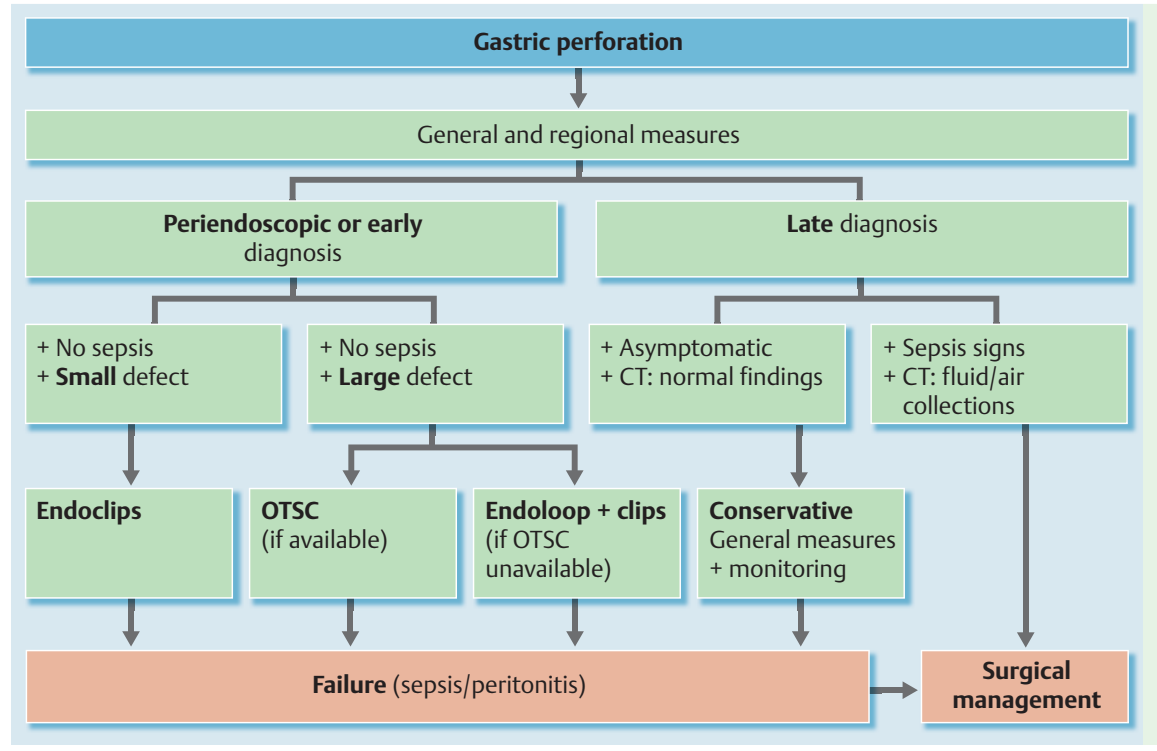

Fig. 1 Algorithm for the management of gastric iatrogenic perforations. CT, computed tomography; OTSC, over-the-scope clip.

Table 3 Results of endoscopic management of gastric perforation with through-the-scope (TTS) clips.

\begin{tabular}{|c|c|c|c|c|c|c|}
\hline First author, year & Type & $\mathbf{n}$ & Pathologies & Technique & Success rate & Others \\
\hline Binmoeller, 1993 [98] & Case report & 1 & Leiomyoma & TTS clipping & $100 \%$ & - \\
\hline Albuquerque, 2004 [99] & Case report & 1 & Adenoma & TTS clipping & $100 \%$ & - \\
\hline Katsinelos, 2004 [100] & Case report & 1 & Adenoma (HGD) & TTS clipping & $100 \%$ & - \\
\hline De Caro, 2009 [101] & Case report & 1 & Adenocarcinoma in situ & TTS clipping & $100 \%$ & - \\
\hline Kim, 2000 [102] & Case report & 1 & Adenocarcinoma in situ & TTS clipping & $100 \%$ & - \\
\hline Tsunada, 2003 [76] & $\begin{array}{l}\text { Retrospective, } \\
\text { case series }\end{array}$ & 7 & Early gastric cancer & $\begin{array}{l}\text { TTS clipping (6) } \\
\text { Omental patch (1) }\end{array}$ & $100 \%$ & 1 large defect \\
\hline Fujishiro, 2006 [18] & $\begin{array}{l}\text { Retrospective, } \\
\text { case series }\end{array}$ & 11 & Early gastric cancer & TTS clipping & $100 \%$ & $\begin{array}{l}\text { Mean discharge time } \\
12.1 \text { days }\end{array}$ \\
\hline Minami, 2006 [63] & Retrospective & 121 & Early gastric cancer & $\begin{array}{l}-<1 \mathrm{~cm} \text { : TTS clipping } \\
->1 \mathrm{~cm} \text { : omental patch }\end{array}$ & $98.3 \%$ & 2 surgeries \\
\hline Total & - & 144 & & - & $>99 \%$ & For defects $<10 \mathrm{~mm}$ \\
\hline
\end{tabular}

HGD, high grade dysplasia

Table 4 Results of endoscopic management of gastric perforation with over-the-scope clips (OTSCs).

\begin{tabular}{|llclclll} 
First author, year & Type & $\mathbf{n}$ & Perforation cause & OTSCs, $\mathbf{n}$ & Success rate & Size \\
\hline Baron, 2012 [71] & Retrospective & 2 & latrogenic & 2 & $100 \%$ & - \\
\hline Kirschniak, 2011 [70] & Retrospective & 7 & latrogenic (1 ESD) & 7 & $100 \%$ & - \\
\hline Voermans, 2012 [2] & Prospective & 6 & latrogenic: ESD, EMR, EUS & 6 & $100 \%$ & $<30 \mathrm{~mm}$ \\
\hline Nishiyama, 2013 [72] & Retrospective & 7 & latrogenic: ESD, scope/ulcer & 13 & $86 \%(6 / 7)$ & $\begin{array}{l}\text { Mean diameter } 30 \mathrm{~mm} \\
1 \text { failure, } 50 \mathrm{~mm}\end{array}$ \\
\hline Total & & 22 & latrogenic & 28 & $95 \%$ & For 10-mm to 30 -mm defects \\
\hline
\end{tabular}

ESD, endoscopic submucosal dissection; EMR, endoscopic mucosal resection; EUS, endoscopic ultrasound. 
Table 5 Results of endoscopic management of gastric perforation with omental patch, band ligation, or the combined technique using endoclips plus endoloop

\begin{tabular}{|c|c|c|c|c|c|c|}
\hline First author, year & Type & $\mathbf{n}$ & Perforation cause & Method & $\begin{array}{l}\text { Success } \\
\text { rate }\end{array}$ & Size \\
\hline Minami, 2006 [63] & Retrospective & 121 & latrogenic perforations (ESD/EMR) & Omental patch & $98.3 \%$ & $>10 \mathrm{~mm}$ \\
\hline Tsunada, 2003 [76] & Case report & 1 & After EMR procedure & Omental patch & $100 \%$ & Large perforation \\
\hline Han, 2013 [64] & Case series & 5 & After ESD (3), EMR (1), biopsy (1) & Band ligation & $100 \%$ & 5 to $11 \mathrm{~mm}$ \\
\hline Shi, 2013 [103] & Retrospective & 20 & Full-thickness resections of tumors & Endoloop + endoclips & $100 \%$ & $\begin{array}{l}\text { Median size } 15 \mathrm{~mm} \\
(0.4-30)\end{array}$ \\
\hline Zhong, 2012 [104] & Retrospective & 14 & Full-thickness resections of tumors & Endoloop + endoclips & $100 \%$ & 0.6 to $30 \mathrm{~mm}$ \\
\hline
\end{tabular}

ESD, endoscopic submucosal dissection; EMR, endoscopic mucosal resection

troenteric anastomosis, or dilation of an antral stricture, or related to cystogastrostomy [77].

The nonsurgical treatment of gastric perforations should include placement of a nasogastric tube under endoscopic control. It should be connected to suction for 1 day after the treatment of the perforation [63].

\section{Perivaterian (periampullary) and biliopancreatic ductal perforation}

\section{High risk procedures: ERCP-related perforations}

The most common causes of perforations related to endoscopic retrograde cholangiopancreatography (ERCP) are sphincterotomy (56\%) and guidewire manipulation (23\%). ESGE suggests that precut, Billroth II gastrectomy, and biliary stricture dilation should be considered to entail increased risk for biliopancreatic perforation. In a review of studies that reported on ERCP-related complications of any type in a total of 16855 patients, amongst whom $50 \%-100 \%$ had undergone a therapeutic procedure depending on individual studies, perforation was reported in 101 patients $(0.6 \%, 95 \%$ confidence interval $[\mathrm{CI}] 0.48-0.72)$ with a perforation-related mortality of $9.90 \%(95 \%$ [Cl] 3.96-15.84) [105]. Other studies listed in $\bigcirc$ Table 6 reported ERCP-related perforations in any location and in the periampullary area/biliopancrea- tic ducts in $0.43 \%(95 \% \mathrm{CI} 0.37-0.59)$ and $0.33 \%(95 \% \mathrm{CI} 0.28-$ 0.48 ), respectively, of 115747 patients.

The causes of perforation were endoscopic sphincterotomy, guidewire manipulation, stricture dilation, and stent insertion or migration in $56 \%, 23 \%, 4 \%$, and $3 \%$ of cases, respectively; perforations were located in the periampullary area, the bile ducts and the pancreatic ducts in $65 \%, 25 \%$, and $1.4 \%$ of cases, respectively $(\bullet$ Table 7$)$.

Independent risk factors for ERCP-related perforations include precut, Billroth II gastrectomy, intramural injection of contrast medium, procedure duration, sphincter of Oddi dysfunction, a dilated common bile duct, and biliary stricture, as identified in two studies [106,107].

ESGE recommends that ERCP-related perforations be described according to the classification by Stapfer et al.: type I, lateral or medial wall duodenal perforation; type II, perivaterian injuries; type III, distal bile duct injuries; type IV retroperitoneal air alone [108].

\section{Treatment: ERCP-related perforations}

The majority of ERCP-related ductal or periampullary duodenal perforations can be managed nonsurgically. The indications for surgery are a major contrast medium leak, severe sepsis despite nonsurgical management, severe peritonitis, and fluid collections or unsolved problems (e.g., retained hardware) that cannot be
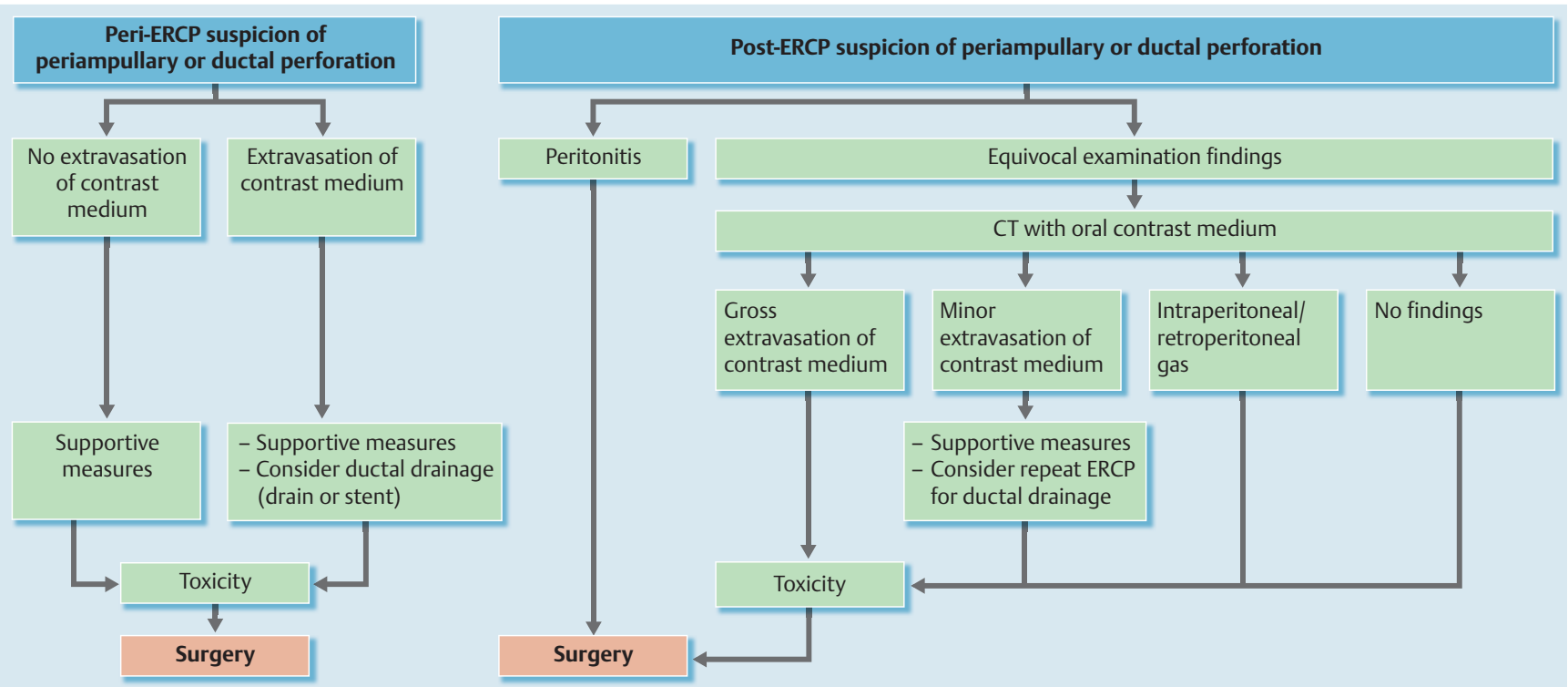

Fig. 2 Algorithm for the management of iatrogenic perforations (types II, III, IV, according to Stapfer et al. [108]) related to endoscopic retrograde cholangiopancreatography (ERCP). 
Table 6 Incidence of perforations related to endoscopic retrograde cholangiopancreatography (ERCP), and requirement for surgery.

\begin{tabular}{|c|c|c|c|c|c|c|c|}
\hline \multirow[t]{2}{*}{ First author, year } & \multirow[t]{2}{*}{ Study design } & \multirow[t]{2}{*}{$\mathbf{n}$} & \multicolumn{2}{|c|}{ Perforation } & \multicolumn{2}{|c|}{ Type II, III, IV ${ }^{1}$} & \multirow{2}{*}{$\begin{array}{l}\text { Surgery required in } \\
\text { types II, III, IV, n }\end{array}$} \\
\hline & & & $\mathbf{n}$ & $\%$ & n & $\%$ & \\
\hline Assalia, 2007 [120] & Prospective & 3104 & 22 & 0.70 & 20 & 0.64 & 1 \\
\hline Avgerinos, 2009 [121] & Retrospective & 4358 & 15 & 0.34 & 6 & 0.13 & 5 \\
\hline Dubecz, 2012[122] & Retrospective & 12232 & 11 & 0.08 & 4 & 0.03 & 1 \\
\hline Enns, 2002 [106] & Retrospective & 9314 & 33 & 0.35 & 28 & 0.30 & 3 \\
\hline Fatima, 2007 [28] & Retrospective & 12427 & 75 & 0.60 & 67 & 0.53 & 15 \\
\hline Howard, 1999 [110] & Retrospective & 6040 & 40 & 0.66 & 36 & 0.59 & 1 \\
\hline Kayhan, 2004 [115] & Retrospective & 3124 & 17 & 0.54 & 15 & 0.48 & 4 \\
\hline Kim, 2011 [123] & Retrospective & 7638 & 13 & 0.17 & 9 & 0.11 & 4 \\
\hline Kim, 2012 [124] & Retrospective & 11048 & 68 & 0.61 & 55 & 0.49 & Not reported \\
\hline Knudson, 2008 [116] & Retrospective & 4919 & 32 & 0.65 & 26 & 0.52 & 8 \\
\hline Kwon, 2012 [125] & Retrospective & 8381 & 53 & 0.63 & 32 & 0.38 & 1 \\
\hline Mao, 2008 [126] & Retrospective & 2432 & 9 & 0.37 & 9 & 0.37 & 3 \\
\hline Morgan, 2009 [127] & Retrospective & 12817 & 24 & 0.18 & 12 & 0.09 & 0 \\
\hline Polydorou, 2011 [12] & Retrospective & 9880 & 44 & 0.44 & 37 & 0.37 & 6 \\
\hline Stapfer, 2000 [108] & Retrospective & 1413 & 14 & 0.99 & 9 & 0.63 & 4 \\
\hline Wu, 2006 [128] & Retrospective & 6620 & 30 & 0.45 & 25 & 0.37 & 7 \\
\hline Total & & 115747 & 500 & 0.43 & 390 & 0.33 & $63(18.8 \%)^{2}$ \\
\hline
\end{tabular}

${ }^{1}$ According to Stapfer's classification [108] (type I, lateral or medial wall duodenal perforation; type II, perivaterian injuries; type III, distal bile duct injuries, type IV retroperitoneal air alone).

${ }^{2}$ Percentage was calculated after exclusion of the results reported by Kim et al. [124].

Table 7 Assumed etiology of 405 type II, III, IV 1 perforations related to endoscopic retrograde cholangiopancreatography (ERCP).

\begin{tabular}{|c|c|c|c|c|c|c|}
\hline First author, year & $\begin{array}{l}\text { Endoscopic } \\
\text { sphincterotomy, } \mathbf{n}\end{array}$ & Guidewire, n & $\begin{array}{l}\text { Dilation of stric- } \\
\text { tures, } \mathbf{n}\end{array}$ & $\begin{array}{l}\text { Other } \\
\text { instruments, } \mathrm{n}\end{array}$ & $\begin{array}{l}\text { Stent insertion } \\
\text { or migration, } \mathbf{n}\end{array}$ & Unknown, $\mathrm{n}$ \\
\hline Alfieri, 2013 [112] & 15 & 1 & - & - & - & 8 \\
\hline Assalia, 2007 [120] & 17 & 2 & - & - & 1 & - \\
\hline Avgerinos, 2009 [121] & 3 & - & - & 3 & - & - \\
\hline Dubecz, 2012 [122] & 3 & 1 & - & - & - & - \\
\hline Enns, $2002[106]$ & 13 & 13 & 2 & - & - & - \\
\hline Fatima, 2007 [28] & 11 & 24 & 5 & 9 & 7 & 11 \\
\hline Howard, 1999 [110] & 22 & 14 & - & - & - & - \\
\hline Kayhan, 2004 [115] & 15 & - & - & - & - & - \\
\hline Kim, 2011 [123] & 3 & 4 & - & 2 & - & - \\
\hline Kim, 2012 [124] & 25 & 23 & - & 2 & - & - \\
\hline Knudson, 2009 [116] & 11 & - & - & - & 3 & 8 \\
\hline Kwon, 2012 [125] & 24 & 2 & 6 & & & - \\
\hline Mao, 2008 [126] & 9 & - & - & - & - & - \\
\hline Morgan, 2009 [127] & 12 & - & - & - & - & - \\
\hline Polydorou, 2011 [12] & 30 & 2 & 2 & 3 & - & - \\
\hline Stapfer, 2000 [108] & 6 & 3 & - & - & - & - \\
\hline Wu, 2006 [128] & 11 & 7 & - & - & - & 7 \\
\hline Total & $230(56 \%)$ & $96(23 \%)$ & $15(3.7 \%)$ & $19(4.6 \%)$ & $11(2.7 \%)$ & $34(8 \%)$ \\
\hline
\end{tabular}

${ }^{1}$ According to Stapfer's classification (type I, lateral or medial wall duodenal perforation; type II, perivaterian injuries; type III, distal bile duct injuries, type IV retroperitoneal air alone) [108]

solved by nonsurgical means. After careful patient selection, nonsurgical management is successful in more than $90 \%$ of patients.

An algorithm ( Fig. 2) summarizes ESGE's recommendations on how to select the most individually appropriate management of ductal or periampullary duodenal ERCP-related perforation. In patients initially managed nonsurgically following ductal or periampullary ERCP-related perforation, the morbidity and mortality rates were $7 \%$ and $3 \%$, respectively; surgery was eventually required in approximately $6 \%$ of cases. These figures were calculated for the 220 patients included in seven studies ( Table 8). No significant difference was found between patients with type II vs. type III perforation, after initial nonsurgical management, in terms of final requirement for surgery, morbidity, or mortality.
A recent review of duodenal, periampullary, and ductal ERCPrelated perforations found that nonsurgical management, applied in $62 \%$ of patients, was successful in $92.9 \%$ of those patients [109]. In 335 patients with ductal or periampullary perforation and final outcome detailed in Table6, surgery was required in $19 \%$ of the cases.

Early diagnosis and prompt treatment are vital for a better outcome $[110,111]$. The choice between surgical vs. nonsurgical management should be guided by the site and degree of the leak and by the patient's condition [106,109,111-114]. Suspected ductal and periampullary perforations should be assessed by an early contrast medium study, during ERCP or using CT scan, and documentation should be retained for medicolegal purposes. 


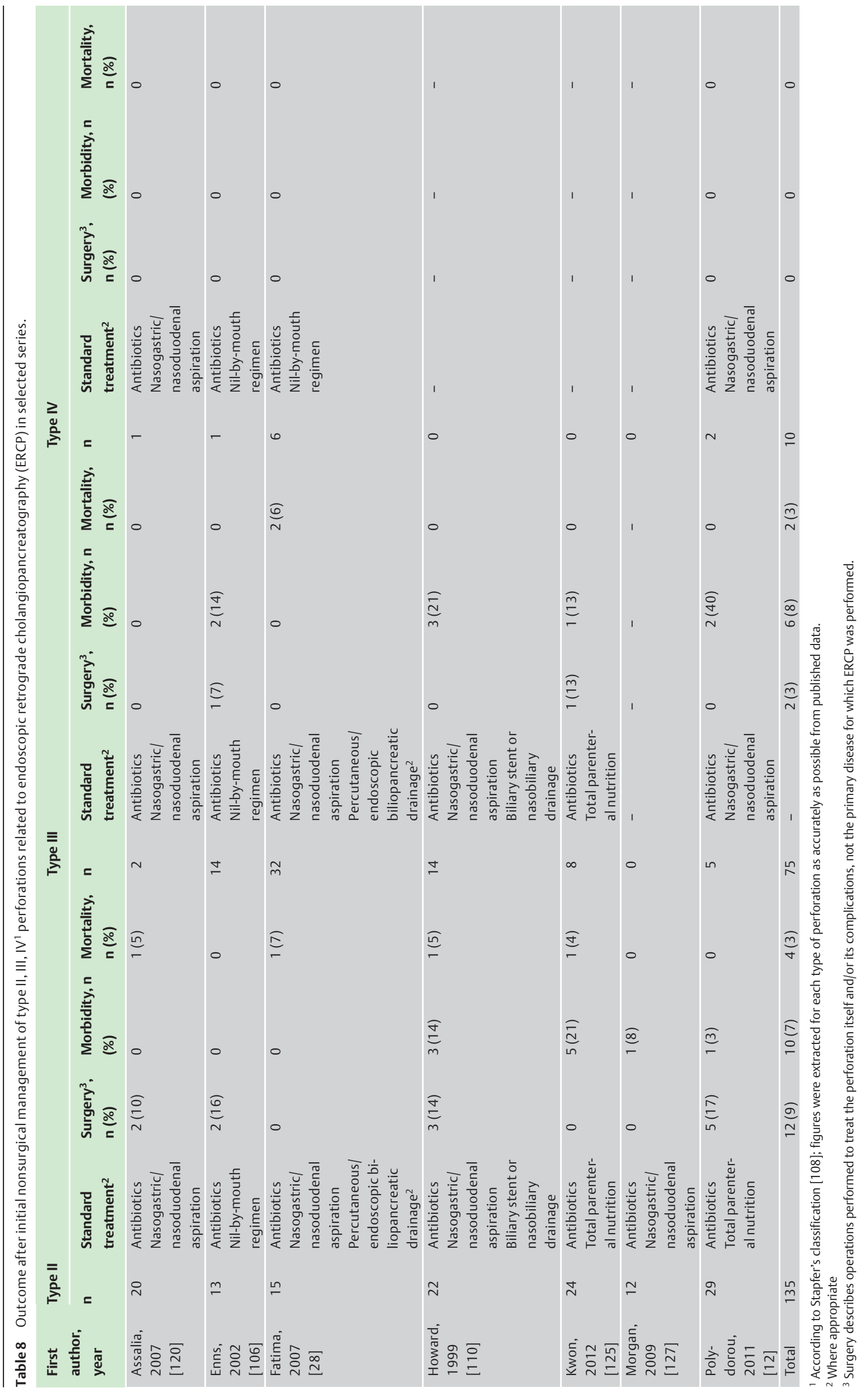


Major periampullary or ductal contrast medium leaks are usually recognized as an indication for immediate surgery [109,111].

For the nonsurgical management of ERCP-related ductal or periampullary duodenal perforation, ESGE recommends antibiotics and nasogastric or nasoduodenal aspiration in all patients; stenting of the perforated duct (or of the biliary duct in the case of periampullary perforation) on a case-by-case basis; and total parenteral nutrition in undernourished patients as well as in patients in whom adequate enteral feeding is presumed not to be feasible for $\geq 7$ days. Cross-sectional imaging should be performed during follow-up and, if a liquid collection is disclosed, percutaneous drainage should be considered. The efficacy of TTS clips in closing periampullary perforations is unknown.

Modalities available for the nonsurgical management of ERCPrelated ductal or periampullary duodenal perforation include:

- Antibiotics and nasogastric or nasoduodenal aspiration, used in most case series.

- Stenting, consistently used by some authors to divert fluids from the perforation site, $[110,112]$ but on a case-by-case basis by others (e.g., in 12 [48\%] of 25 patients treated nonoperatively by Enns et al.), with no significantly different results [106]. Another concern about stenting is the impact of abandoning scheduled ERCP tasks because of recognition of perforation during the ERCP procedure. Following ERCP-related perforation, a significant proportion of patients may refuse ERCP and prefer surgery although repeat ERCP has been reported to succeed in treating the primary biliopancreatic disease in up to $100 \%$ of patients [106,115].

- Total parenteral nutrition, mentioned in a single study [12], is recommended in European guidelines for postoperative parenteral nutrition if complications impede adequate enteral feeding for at least 7 days and in undernourished patients [27]. Using mean duration of hospital stay as a proxy for the fasting period following ERCP-related perforation, we conclude that total parenteral nutrition is required in a minority only of wellnourished patients who are successfully treated nonoperatively.

- Abdominal fluid collections are commonly drained percutaneously in the first place; this was performed in $13(6 \%)$ of the 209 patients listed in Table 8 with wide variations between studies (0 to 20\%). Endosonography-guided transenteric stenting has been proposed as an alternative for draining bilomas [113].

- TTS clips have been used by some authors in an attempt to close perforations, but in the absence of controlled trials the true efficacy of this measure is unknown $[28,112,116]$.

- Somatostatin has not been tested in patients with a peri-ERCP pancreatic duct perforation. It improves closure of postoperative enterocutaneous fistulas compared with placebo [117119].

\section{Duodenal and small bowel perforation}

$\nabla$

High risk procedures: duodenum and small bowel

ESGE suggests that altered anatomy, stricture dilation in Crohn's disease, dilation of gastrojejunal stricture after gastric bypass, endoscopic submucosal dissection (ESD) and, in patients with altered anatomy, double-balloon enteroscopy (DBE) are risk factors for duodenal and small-bowel perforation.

\section{Duodenum: high risk procedures}

In a retrospective case series of 72 iatrogenic perforations following esophagogastroduodenoscopy (EGD), the incidence of perforation was $0.033 \%$ ( 25 were in the duodenum, for an incidence of $0.01 \%$ ) [62].

Perforations of the lateral or medial wall of the duodenum caused by the endoscope itself (type I in Stapfer's classification) are usually large and carry a high mortality (28\% in the study by Merchea et al.) [62,108]. The main risk factor for this type of perforation is Billroth II gastrectomy [124].

Among therapeutic procedures, ESD has a particularly high risk of perforation, with a perforation rate of $35.7 \%$ reported in a retrospective study of 14 patients [129]. Delayed perforation after ESD is more frequent in the duodenum (14\%) than after gastric $(0.45 \%)$ and colorectal ESD $(0.3 \%-0.7 \%)$ [ $130-132]$. The high incidence of delayed perforations may be due to the thinness of the duodenal wall, coupled with proteinolysis or chemical irritation by pancreatic enzymes and bile juice. However, endoscopic mucosal resection (EMR) seems to be safe in the duodenum. No case of perforation was reported in two studies evaluating 47 cases in total $[133,134]$.

\section{Small bowel: high risk procedures}

DBE-related perforations in the small bowel are rare. In a German prospective study of 2245 DBE examinations, only 3 perforations were observed (incidence $0.1 \%$ ), with 2 of these occurring after polypectomy ( $1.5 \%$ of 137 polypectomies) [135]. A large retrospective study of DBE complications in nine US centers showed a iatrogenic perforation rate of $0.4 \%$ with a significantly higher incidence of iatrogenic perforations in patients with altered surgical anatomy (3\%) [136]. In the last 5 years there have been three case reports describing capsule endoscopy in patients with Crohn's disease leading to retention and perforation [137-139]. One perforation is reported in a small prospective case series $(\mathrm{n}=$ 13) of DBE with stricture dilation in Crohn's disease [140]. Dilation of gastrojejunal anastomotic strictures after gastric bypass surgery carries an iatrogenic perforation rate of between 0 and $4.5 \%[141]$.

\section{Treatment: duodenum and small bowel}

In type I (i.e. nonperivaterian) duodenal perforations, ESGE recommends endoscopic treatment if the iatrogenic perforation is recognized immediately and, in the case of failure of endoscopic treatment, immediate surgery. If the duodenal perforation is diagnosed later (>12h), management should be surgical in the case of contrast medium extravasation or of persistent large fluid collection at CT scan, or if the patient's condition deteriorates. If the patient is in good condition without extravasation of contrast medium or persistent large fluid collection seen at $C T$, the patient should be treated conservatively without intervention.

For iatrogenic perforations in the small bowel, ESGE recommends surgical treatment although some iatrogenic perforations caused by dilation of stricture at a gastrojejunal anastomosis (GJA) may be treated conservatively.

\section{Duodenum: treatment}

In the case of immediate recognition of perforation, an endoscopic closure should be attempted. This is effective in a minority of cases only (17 [22\%] of 76 cases listed in Table 9). In the 76 cases listed in Table 9 endoscopic closure was possible in 18 
Table 9 Reports of treatments of duodenal iatrogenic perforation (type I) since September $2008^{1}$

\begin{tabular}{|c|c|c|c|c|c|c|c|}
\hline First author, year & $\mathbf{n}$ & Procedure & $\begin{array}{l}\text { Endoscopic closure, } \\
\text { n (system used) }\end{array}$ & Surgery, n & Conservative, $n$ & Standard treatment & $\begin{array}{l}\text { Mortality, } \\
\text { n (\%) }\end{array}$ \\
\hline Avgerinos, 2009 [121] & 9 & ERCP & & 9 & - & - & 0 \\
\hline Palanivelu, 2008 [144] & 1 & ERCP & & 1 & - & $\begin{array}{l}\text { Broad spectrum antibiotics } \\
\text { + Nil-by-mouth regimen } \\
\text { + Nasoduodenal aspiration } \\
\text { + Parenteral nutrition }\end{array}$ & 0 \\
\hline Ahlawat, 2009 [145] & 1 & EUS & 1 (endoclips) & - & - & $\begin{array}{l}\text { Broad spectrum antibiotics } \\
+ \text { Nil-by-mouth regimen }\end{array}$ & 0 \\
\hline Honda, 2009 [146] & 2 & ESD & 1 (endoclips) & $\begin{array}{l}1 \text { (delayed } \\
\text { perforation) }\end{array}$ & - & - & 0 \\
\hline Nakagawa, 2010 [147] & 1 & ERCP & $\begin{array}{l}1 \text { (endoclip + endo- } \\
\text { loops) }\end{array}$ & - & - & $\begin{array}{l}\text { Broad spectrum antibiotics } \\
\text { + Nil-by-mouth regimen } \\
\text { + Parenteral nutrition } \\
\text { + Proton pump inhibitor }\end{array}$ & 0 \\
\hline Farhat, 2011 [148] & 1 & ESD & 1 (endoclips) & - & - & - & 0 \\
\hline Lee, 2010 [149] & 4 & ERCP & 4 (endoclips) & - & - & $\begin{array}{l}\text { Broad spectrum antibiotics } \\
\text { + Parenteral nutrition } \\
\text { + Proton pump inhibitor }\end{array}$ & 0 \\
\hline Polydorou, 2011 [12] & 7 & ERCP & - & 6 & 1 & - & $2(29)$ \\
\hline Ercan, 2012 [150] & 17 & ERCP & - & 17 & & $\begin{array}{l}\text { Broad spectrum antibiotics } \\
\text { + Nil-by-mouth regimen } \\
\text { + Nasoduodenal aspiration }\end{array}$ & $8(47)$ \\
\hline Kim, 2012 [124] & 9 & ERCP & - & 8 & 1 & Broad spectrum antibiotics & $\begin{array}{l}\text { Not } \\
\text { reported }\end{array}$ \\
\hline Fanning, 2012 [151] & 1 & ERA & 1 (endoclips) & & & Broad spectrum antibiotics & 0 \\
\hline $\begin{array}{l}\text { Samarasena, } 2012 \\
\text { [152] }\end{array}$ & 1 & ERA & $\begin{array}{l}1 \text { (endoclips, endo- } \\
\text { loop, and fibrin glue) }\end{array}$ & - & - & $\begin{array}{l}\text { Broad spectrum antibiotics } \\
\text { + Nil-by-mouth regimen } \\
\text { + Nasoduodenal aspiration }\end{array}$ & 0 \\
\hline Hadj Amor, 2012 [96] & 1 & EMR & $\begin{array}{l}\text { (OTSC, endoclips, } \\
\text { and stent) }\end{array}$ & - & - & - & 0 \\
\hline Gubler, 2012 [153] & 2 & ERA & 2 (OTSC) & & - & $\begin{array}{l}\text { Broad spectrum antibiotics } \\
+ \text { Nil-by-mouth regimen }\end{array}$ & 0 \\
\hline $\begin{array}{l}\text { Matsumoto, } 2013 \\
\text { [154] }\end{array}$ & 3 & ESD & - & 2 & 1 & - & 0 \\
\hline Rabie, 2013 [155] & 10 & ECRP & - & 3 & 7 & - & $1(10)$ \\
\hline Nishiyama, 2013 [72] & 1 & ESD & 1 (OTSC) & - & - & - & - \\
\hline Jung, 2013 [129] & 5 & ESD & 3 (endoclips) & 2 & - & Nasoduodenal aspiration & - \\
\hline Summary & 76 & & 17 & 49 & 10 & - & $11(16)$ \\
\hline
\end{tabular}

ERCP, endoscopic retrograde cholangiopancreatography; EUS, endoscopic ultrasound; ESD, endoscopic submucosal dissection; ERA, endoscopic resection of adenomas; EMR, endoscopic mucosal resection; OTSC; over-the-scope clip.

${ }^{1}$ Several reports fail to inform about standard treatment and the management of the perforation.

(24\%) cases and it was successful in 17 (clinical success rate after successful endoscopic closure of duodenal perforation, 94.4\%). In the 17 cases with successful endoscopic closure, 11 perforations with a maximum diameter of $13 \mathrm{~mm}$ were successfully treated with TTS clips, 2 perforations of $10 \mathrm{~mm}$ and $30 \mathrm{~mm}$ were treated with a combination of TTS clips and endoloops, and 4 perforations with a maximum diameter of $28 \mathrm{~mm}$ were treated with an OTSC. The dimensions of the lesion are rather unclear in the articles but in most cases the number indicates the maximum lesion size. Immediate endoscopic closure is believed to be technically easier compared with a delayed attempt because the perforation margins are soft, not yet being involved by inflammation [72]. A successful therapeutic ERCP following treatment with an OTSC for acute duodenal perforation that occurred during diagnostic endoscopic ultrasonography (EUS) has been reported [142].

If the iatrogenic perforation is diagnosed several hours after the endoscopy and the patient shows symptoms of generalized peritonitis and/or sepsis, the only option is surgery. Avgerinos et al. found in a retrospective review of 15 cases of duodenal iatrogenic perforations that mortality dramatically increases with late $(>24$ h) surgical management [121]. These authors described a clinicoradiographic test to choose between a surgical or a conservative treatment for ERCP-related duodenal iatrogenic perforation. If an abdominal radiograph showed free intraperitoneal air, an abdominal CT scan with oral water-soluble contrast was carried out. Extravasation of contrast in the intra-abdominal cavity or the presence of extradigestive fluid indicated surgical exploration, whereas nonsurgical treatment was possible in the absence of these factors ( Fig. 3) [121].

\section{Small bowel: treatment}

- Table 10 summarizes the case reports on treatments of smallbowel iatrogenic perforations published since September 2008. Out of 32 patients with small-bowel iatrogenic perforations, 19 underwent surgery, 5 patients were treated conservatively, 1 laceration was closed with an OTSC and in 7 cases the management was not reported. All of the 5 patients who were treated conservatively had iatrogenic perforations following endoscopic dilation of a GJA. 


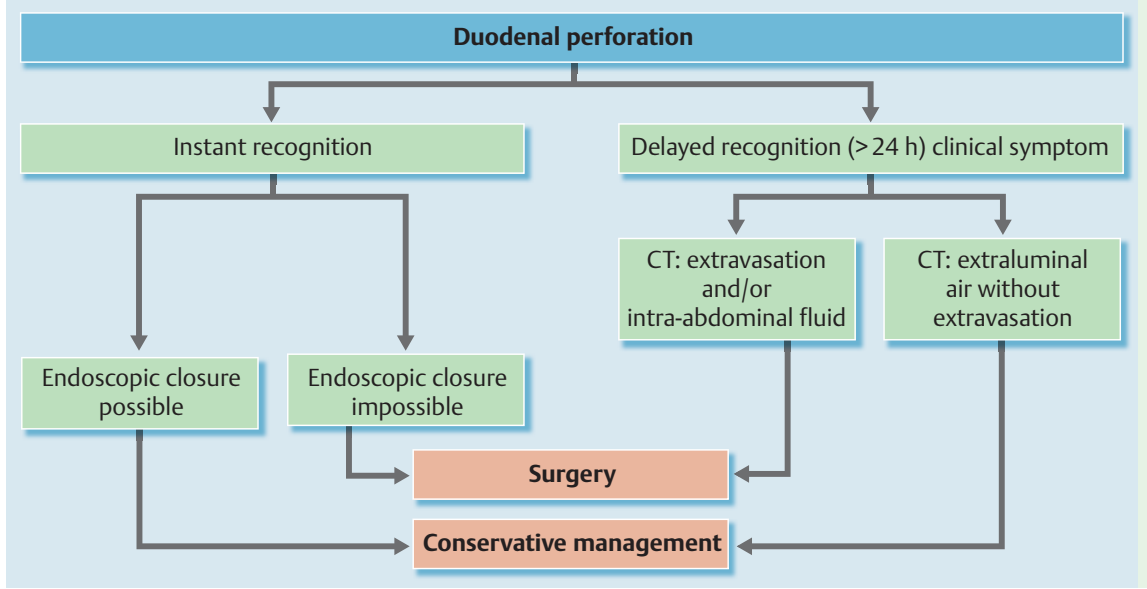

Fig. 3 Algorithm for the management of duodenal iatrogenic perforations (type I). CT, computed tomography.

Table 10 Reports of treatments of small-bowel perforation since September 2008.

\begin{tabular}{|c|c|c|c|c|c|c|c|}
\hline First author, year & $\mathbf{n}$ & Procedure & $\begin{array}{l}\text { Endoscopic } \\
\text { closure, } n \\
\text { (system used) }\end{array}$ & Surgery, $\mathbf{n}$ & Conservative, $\mathbf{n}$ & Standard treatment ${ }^{1}$ & $\begin{array}{l}\text { Mortality } \\
\text { (\%) }\end{array}$ \\
\hline Um, 2008 [139] & 1 & Capsule endoscopy & - & 1 & - & - & 0 \\
\hline Gerson, 2009 [136] & 10 & DBE & - & 10 & - & - & $1(10)$ \\
\hline Despott, 2009 [140] & 1 & DBE & - & 1 & - & - & 0 \\
\hline Teruel, 2009 [156] & 1 & Colonoscopy & - & 1 & - & - & 0 \\
\hline Möschler, $2011^{1}$ [135] & 3 & DBE & - & - & - & - & 0 \\
\hline Campos, $2012^{1}$ [157] & 14 & Dilation of GJA & - & 5 & 5 & $\begin{array}{l}\text { Broad spectrum } \\
\text { antibiotics } \\
+ \text { Nil-by-mouth } \\
\text { regimen }\end{array}$ & 0 \\
\hline Yitzhak, 2012 [138] & 1 & Capsule endoscopy & - & 1 & - & - & 0 \\
\hline Balmadrid, 2013 [143] & 1 & SBE-PEJ & OTSC & - & - & $\begin{array}{l}\text { Broad spectrum } \\
\text { antibiotics }\end{array}$ & 0 \\
\hline Summary & 32 & & 1 & 19 & 5 & - & $1(3)$ \\
\hline
\end{tabular}

DBE, double-balloon enteroscopy; GJA, gastrojejunal anastomosis; SBE-PEJ, single balloon enteroscopy-percutaneous endoscopic jejunostomy

${ }^{1}$ No description of the management of all perforations.

Until recently surgery has been the only choice for management and only one case report, as mentioned above, describes an endoscopic closure, using the OTSC system, of a small-bowel laceration near the ligament of Treitz [143].

Surgery should still be the first choice in the management of small-bowel iatrogenic perforations.

\section{Colorectal perforations}

\section{High risk procedures in the colorectum}

ESGE recommends that complex EMR, ESD, and balloon dilation procedures should be considered to carry increased risk of colorectal perforation.

Older age, co-morbidity, inflammatory colonic disease, use of hot biopsy forceps, and endoscopist inexperience are other significant risk factors for iatrogenic perforations at colonoscopy.

Risk factors include female gender, presumably related to pelvic adhesions, major co-morbidities and greater age (weakened colonic wall tissues) $[13,158-160]$. Risk may also be increased during surveillance colonoscopy in patients with colitis such as inflammatory bowel disease [161]; however, the colonoscopic surveillance for long-standing extensive ulcerative colitis has proved to be safe with no significant complications when biopsies are obtained with caution [162].
The sigmoid colon and the rectosigmoid junction are the most common sites of diagnostic perforation due to direct mechanical injury via shearing forces applied by the shaft or tip of the colonoscope during endoscope insertion [14,163]. Pericolic adhesions (from previous gynecological surgery or abdominal inflammation) and severe diverticular disease may increase the risk of perforation, particularly when large-caliber instruments and excessive force are used [164]. Traumatic antimesenteric tears of the colonic wall are less common elsewhere but can occur at the flexures because of excessive tip force or in the rectum during retroflexion [165]. Cecal perforation can also occur because of barotrauma, particularly if gas is introduced above an area of stenosis [166]; barotrauma is probably less likely when carbon dioxide is used, compared with air, as the former is absorbed more quickly.

Iatrogenic perforation has been reported in $0.03 \%-0.8 \%$ of diagnostic colonoscopies and flexible sigmoidoscopies in both the symptomatic and screening settings [167-169].

Therapeutic colonoscopy carries a small but significant risk of perforation (up to $5 \%$ ), particularly following advanced polypectomy. However, high risk procedures such as endoscopic balloon dilation, applied to treat ileocolonic anastomotic strictures as in Crohn's disease, may entail perforation rates up to $11 \%$ [170]. Regarding the use of SEMSs in the setting of acute malignant colonic obstruction, retrospective studies demonstrate a perforation rate 
of $5 \%-9 \%[171,172]$. The British Society of Gastroenterology (BSG) audit of colonoscopy demonstrated that the risk of perforation at diagnostic examinations was 1:923 compared with 1:460 following polypectomy [173]. The Munich Polypectomy Study reports a risk of $1.1 \%$ for colorectal perforation when polyps were larger than $10 \mathrm{~mm}$ in the right colon or $20 \mathrm{~mm}$ in left colon or when there were multiple polyps [174]. Equivalent results were reported by a French national survey, reporting a perforation rate of $3.6 \%$ after EMR polypectomy in the lower gastrointestinal tract [175].

For piecemeal EMR of polyps larger than $20 \mathrm{~mm}$, two experienced centers reported acceptably low perforation rates of $1.3 \%$ and $0.003 \%[176,177]$. Conversely, the perforation rate for colorectal ESD is higher but varies depending on the experience of the operator. Predictive risk factors for iatrogenic perforations during colorectal ESD such as submucosal fibrosis and tumor size should be also considered because they may complicate ESD, being associated with a higher perforation incidence of $20.4 \%$ [178]. Early Japanese experience with ESD showed a perforation risk of $5 \%-10 \%$, although current literature demonstrates a lower perforation risk ranging from $1.9 \%$ to $4.7 \%$ [179, 180]. An early multicenter report of colorectal ESD from France reported a high perforation rate (18.1\%) [148]; but more recently other centers have described more acceptable perforation rates of $2 \%-12 \%$, in line with the early experience from Japan [181]. In the past, hot biopsy forceps have been applied to destroy small polyps but recent animal studies demonstrate a potential hazard for deep thermal injury with transmural necrosis found in a high proportion of cases [182]. Anecdotal reports of delayed hemorrhage and perforation following hot biopsy have led many centers to abandon the use of this technique particularly in the right colon.

The risk of iatrogenic perforation appears to be operator-dependent; non-gastroenterologist endoscopists and endoscopists who perform only a low number of cases being associated with an increased risk of iatrogenic perforation $[1,159]$.

Investigations such as abdominal plain film radiography or CT scan are commonly performed in the case of clinically suspected or diagnosed perforation to verify the presence of air or fluid collections or injected contrast material. Abdominal CT is the most sensitive examination for detecting gas or liquid leaks [183]; water-soluble contrast enema per rectum is seldom used to detect concealed perforation.

\section{Treatment in the colorectum}

$\nabla$

ESGE recommends the use of TTS endoclips for small holes and OTSCs for larger ones. Adequate colon preparation is an important factor when contemplating endoscopic treatment of iatrogenic perforations. All patients treated conservatively should be watched closely by a multidisciplinary team in the immediate post-procedure period. Immediate surgical repair is required in the case of larger perforations or where endoscopic closure has failed or where the patient's clinical condition is deteriorating.

Air or gas entry into the peritoneal cavity is a hallmark of iatrogenic perforation but does not necessarily cause infective peritonitis unless egress of luminal contents occurs. The recognition of colorectal wall tears may be immediate at the time of the procedure or can be delayed for up to 3 days $[184,185]$.

A conservative strategy is possible when a perforation site is recognized early, enabling an urgent closure without the spillage of gut contents. Rapid endoscopic intervention with clip placement and the use of carbon dioxide may limit the volume of extraluminal insufflation and subsequently the need for surgery [186, 187]. When there is no evidence of intraperitoneal contamination by fecal contents, free air may either resolve spontaneously within a week or progress to a compartment syndrome [188]. In this case, a tension pneumoperitoneum develops requiring an immediate release of trapped intraperitoneal air. However, if fecal contents are present, then the optimal management is surgery.

The decision to attempt endoscopic closure of an iatrogenic perforation depends on multiple factors, including the size and the cause of iatrogenic perforation, the endoscopist's experience and the accessories available at the time. With immediate endo-

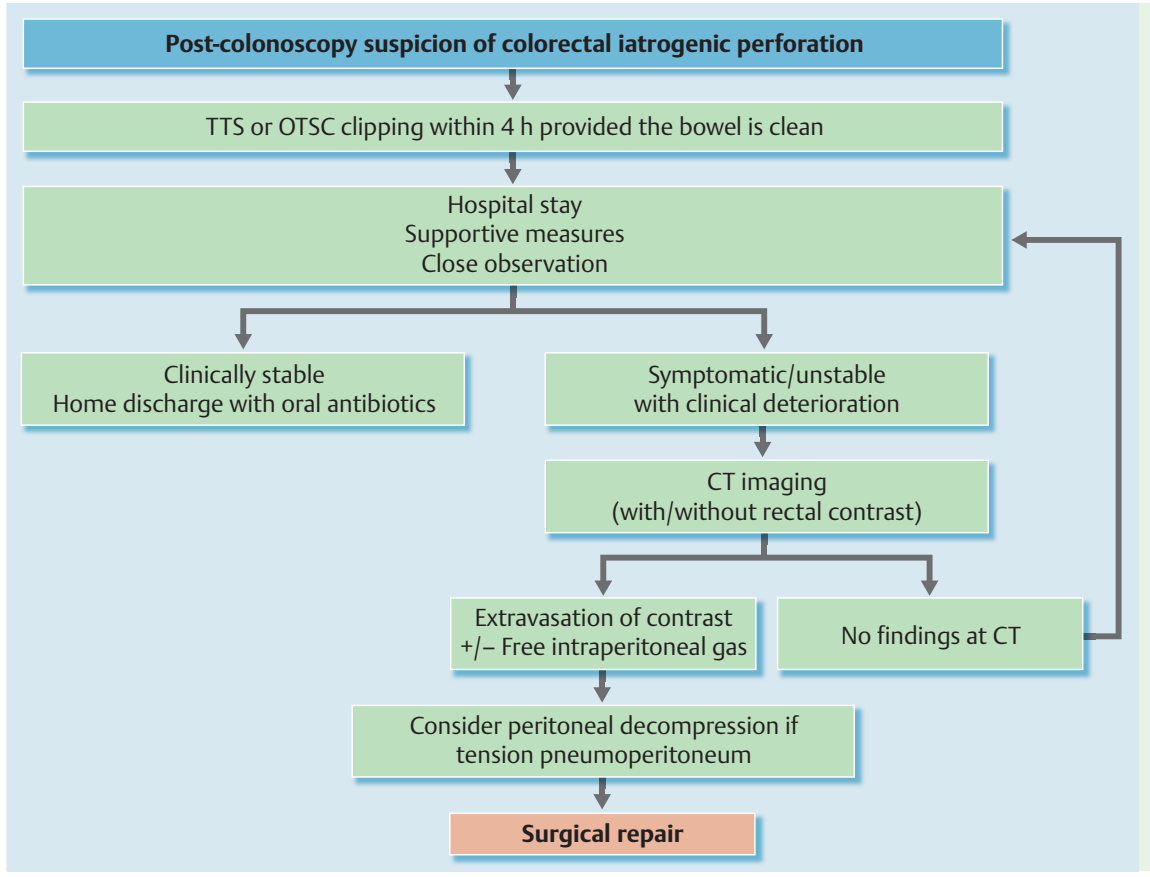

Fig. 4 Algorithm for the management of colonic iatrogenic perforations. TTS, throughthe-scope; OTSC, over-the-scope clip; CT, computed tomography. 
scopic closure of the defect, superficial apposition of the mucosa and submucosal layers seems sufficient to obtain adequate wound healing at the perforation site and to achieve a good nonsurgical outcome [189].

Early endoscopic closure of an iatrogenic perforation smaller than $20 \mathrm{~mm}$, using either TTS clips or OTSC, is likely to be effective, with overall technical and clinical success rates of $93 \%$ and $89 \%$ respectively $[2,190,191]$. Electrocautery injury may induce colorectal perforations which are amenable to both TTS clip and OTSC clipping, in particular during ESD where there is a high risk of microperforation $[68,178]$. It has been reported that TTS clipping is more effective for closure of therapeutic perforations that are less than $10 \mathrm{~mm}$ than for diagnostic perforations where defects are blunter and larger in size [192,193]. Recent systematic reviews based mainly on case series, report that the OTSC technique is also a safe, easy to handle, and efficacious method for treating both diagnostic and therapeutic colorectal perforations $[194,195]$. Band ligation has been reported as a salvage therapy after failed clipping [196].

An early endoscopic sign, during the post-polypectomy examination of the resected polyp, is the "target sign" showing full-thickness muscle tissue surrounded by submucosa [26]. In this case, an iatrogenic perforation is strongly suspected and immediate endoscopic clipping is indicated. Occasionally, a perforation is diagnosed post-procedurally and if preparation is still adequate (within 4 hours after the procedure) endoscopic therapy may also be considered $(\bullet$ Fig. 4 ).

Concomitant administration of intravenous fluids, broad spectrum antibiotics and close monitoring of vital signs are always recommended in each suspected or diagnosed colorectal perforation, to prevent clinical deterioration. Empirical medical treatment should possibly be undertaken promptly, prior to confirmation of perforation by appropriate radiological means.

A clear indication for surgery is a complicated or failed endoscopic closure with an ongoing leak that is causing feculent peritonitis [197]. Minimally invasive laparoscopic treatment of perforations has become the preferred surgical option and is now widely accepted and practiced [198]. Preliminary data have demonstrated that the laparoscopic approach resulted in decreased morbidity and length of hospital stay as well as reduced abdominal wall scarring [199].

\section{Conclusions}

\section{$\nabla$}

Despite the lack of high quality studies, there is substantial evidence, particularly in the colorectum, that a few simple risk factors may be used to stratify the risk of iatrogenic perforation for each organ, allowing anticipation of higher probability of iatrogenic perforation. Moreover, there is compelling evidence that endoscopic treatment by means of clipping or stenting is effec-

Table 11 Main issues for research
- What is the long-term morbidity of iatrogenic perforations successful-
ly treated with clips?
- What is the necessity of carbon dioxide use during ESD?
- What is the feasibility of combined techniques (endoclips + endoloop)
in closing large defects?
- What training is required for inserting OTSCs in the case of iatrogenic
perforations?

ESD, endoscopic submucosal dissection; OTSC, over-the-scope clip tive in the management of iatrogenic perforations, especially for small breaches. Additionally, the wide implementation of CT allows early diagnosis of iatrogenic perforations in subtle cases, preventing harmful delays in conservative or surgical management. All these factors support the implementation of proactive policies to minimize the morbidity and mortality related to iatrogenic perforation. There is an urgent need for high quality studies to clarify the efficacy and safety of the proposed policies. The main issues to be addressed are reported in $\bullet$ Table 11 .

ESGE guidelines represent a consensus of best practice based on the available evidence at the time of preparation. They may not apply in all situations and should be interpreted in the light of specific clinical situations and resource availability. Further controlled clinical studies may be needed to clarify aspects of these statements, and revision may be necessary as new data appear. Clinical consideration may justify a course of action at variance to these recommendations. ESGE guidelines are intended to be an educational device to provide information that may assist endoscopists in providing care to patients. They are not rules and should not be construed as establishing a legal standard of care or as encouraging, advocating, requiring, or discouraging any particular treatment.

\section{Competing interests: None}

\section{Institutions}

${ }^{1}$ Gastroenterology Department, Benizelion General Hospital, Heraklion, Crete, Greece

${ }^{2}$ Gedyt Endoscopy Center, Buenos Aires, Argentina

${ }^{3}$ LBA UMR T24, Faculty of Medicine, Aix-Marseille University, Marseille, France ${ }^{4}$ Endoscopy Unit, Digestive Disease Center, Bispebjerg Hospital, University of Copenhagen, Copenhagen, Denmark

${ }^{5}$ Department of Gastroenterology, Digestive Endoscopy Unit, IRCCS Istituto Clinico Humanitas, Milan, Italy

${ }^{6}$ Wolfson Unit for Endoscopy, St Mark's Hospital \& Imperial College, London, UK

${ }^{7}$ Second Department of Surgery, Aretaieion University Hospital, Athens, Greece

${ }^{8}$ Department of Gastroenterology and Hepatology, Academic Medical Center, University of Amsterdam, Amsterdam, the Netherlands

${ }^{9}$ Digestive Endoscopy Unit, Catholic University, Rome, Italy

\section{References}

1 Bielawska B, Day AG, Lieberman DA et al. Risk factors for early colonoscopic perforation include non-gastroenterologist endoscopists: a multivariable analysis. Clin Gastroenterol Hepatol 2014 2014; 12: $85-92$

2 Voermans RP, Le Moine 0 , von Renteln D. Efficacy of endoscopic closure of acute perforations of the gastrointestinal tract. Clin Gastroenterol Hepatol 2012; 10: 603-608

3 Akobeng AK. Principles of evidence based medicine. Arch Dis Child 2005; 90: 837-840

4 Dumonceau JM, Hassan C, Riphaus A et al. European Society of Gastrointest Endosc (ESGE) Guideline Development Policy. Endoscopy 2012; 44: $626-629$

5 Jauch EC, Saver JL, Adams HP Jr. et al. Guidelines for the early management of patients with acute ischemic stroke: a guideline for healthcare professionals from the American Heart Association/American Stroke Association. Stroke 2013; 44: 870-947

$6 \mathrm{Lu} Y$, Loffroy R, Lau JY et al. Multidisciplinary management strategies for acute non-variceal upper gastrointestinal bleeding. Br J Surg 2014; 101: E34-E50

7 Cotton PB, Eisen GM, Aabakken L et al. A lexicon for endoscopic adverse events: report of an ASGE workshop. Gastrointest Endosc 2010; 71: 446-454 
8 Raju GS, Saito Y, Matsuda T et al. Endoscopic management of colonoscopic perforations (with videos). Gastrointest Endosc 2011; 74: $1380-1388$

9 Baron TH, Wong Kee Song LM, Zielinski MD et al. A comprehensive approach to the management of acute endoscopic perforations (with videos). Gastrointest Endosc 2012; 76: 838-859

10 Jin YJ, Jeong S, Kim JH et al. Clinical course and proposed treatment strategy for ERCP-related duodenal perforation: a multicenter analysis. Endoscopy 2013; 45: 806 -812

11 Kuppusamy MK, Felisky C, Kozarek RA et al. Impact of endoscopic assessment and treatment on operative and non-operative management of acute oesophageal perforation. Br J Surg 2011; 98: 818-824

12 Polydorou A, Vezakis A, Fragulidis $G$ et al. A tailored approach to the management of perforations following endoscopic retrograde cholangiopancreatography and sphincterotomy. J Gastrointest Surg 2011; 15: $2211-2217$

13 Anderson ML, Pasha TM, Leighton JA. Endoscopic perforation of the colon: lessons from a 10-year study. Am J Gastroenterol 2000; 95: 3418 3422

14 Paspatis GA, Vardas E, Theodoropoulou A et al. Complications of colonoscopy in a large public county hospital in Greece. A 10-year study. Dig Liver Dis 2008; 40: 951 - 957

15 Kowalczyk L, Forsmark CE, Ben-David K et al. Algorithm for the management of endoscopic perforations: a quality improvement project. Am J Gastroenterol 2011; 106: 1022 - 1027

16 Carrott PWJr., Low DE. Advances in the management of esophageal perforation. Thorac Surg Clin 2011; 21: 541 - 555

17 Tamiya Y, Nakahara K, Kominato K et al. Pneumomediastinum is a frequent but minor complication during esophageal endoscopic submucosal dissection. Endoscopy 2010; 42: 8-14

18 Fujishiro $M$, Yahagi N, Kakushima $N$ et al. Successful nonsurgical management of perforation complicating endoscopic submucosal dissection of gastrointestinal epithelial neoplasms. Endoscopy 2006; 38 : $1001-1006$

19 Maeda $Y$, Hirasawa D, Fujita $N$ et al. Mediastinal emphysema after esophageal endoscopic submucosal dissection: its prevalence and clinical significance. Dig Endosc 2011; 23: 221 - 226

20 Raju GS, Fritscher-Ravens A, Rothstein RI et al. Endoscopic closure of colon perforation compared to surgery in a porcine model: a randomized controlled trial (with videos). Gastrointest Endosc 2008; 68: 324-332

21 Fritscher-Ravens A, Hampe J, Grange P et al. Clip closure versus endoscopic suturing versus thoracoscopic repair of an iatrogenic esophageal perforation: a randomized, comparative, long-term survival study in a porcine model (with videos). Gastrointest Endosc 2010; 72: $1020-1026$

22 Lin BW, Thanassi W. Tension pneumoperitoneum. J Emerg Med 2010; 38: $57-59$

23 Fu K, Ishikawa T, Yamamoto $T$ et al. Paracentesis for successful treatment of tension pneumoperitoneum related to endoscopic submucosal dissection. Endoscopy 2009; 41: E245

24 Dellon ES, Hawk JS, Grimm IS et al. The use of carbon dioxide for insufflation during GI endoscopy: a systematic review. Gastrointest Endosc 2009; 69: $843-849$

25 Wang $W L, W u Z H$, Sun $Q$ et al. Meta-analysis: the use of carbon dioxide insufflation vs. room air insufflation for gastrointestinal endoscopy. Aliment Pharmacol Ther 2012; 35: 1145-1154

26 Swan MP, Bourke MJ, Moss A et al. The target sign: an endoscopic marker for the resection of the muscularis propria and potential perforation during colonic endoscopic mucosal resection. Gastrointest Endosc 2011; 73: 79-85

27 Braga $M$, Ljungqvist 0 , Soeters $P$ et al. ESPEN guidelines on parenteral nutrition: surgery. Clin Nutr 2009; 28: 378-386

28 Fatima J, Baron TH, Topazian MD et al. Pancreaticobiliary and duodenal perforations after periampullary endoscopic procedures: diagnosis and management. Arch Surg 2007; 142: 448 - 454

29 Castellvi J, Pi F, Sueiras A et al. Colonoscopic perforation: useful parameters for early diagnosis and conservative treatment. Int J Colorect Dis 2011; 26: 1183 - 1190

30 Ben-Menachem T, Decker GA, Early DS et al. Adverse events of upper GI endoscopy. Gastrointest Endosc 2012; 76: 707-718

31 Soreide JA, Konradsson A, Sandvik OM et al. Esophageal perforation: clinical patterns and outcomes from a patient cohort of Western Norway. Dig Surg 2012; 29: 494-502
32 Broor SL, Lahoti D, Bose PP et al. Benign esophageal strictures in children and adolescents: etiology, clinical profile, and results of endoscopic dilation. Gastrointest Endosc 1996; 43: 474-477

33 Karnak I, Tanyel FC, Buyukpamukcu $N$ et al. Esophageal perforations encountered during the dilation of caustic esophageal strictures. J Cardiovasc Surg (Torino) 1998; 39: $373-377$

34 Boeckxstaens GE, Annese V, des Varannes SB et al. Pneumatic dilation versus laparoscopic Heller's myotomy for idiopathic achalasia. N Engl J Med 2011; 364: 1807 - 1816

35 Campos GM, Vittinghoff E, Rabl C et al. Endoscopic and surgical treatments for achalasia: a systematic review and meta-analysis. Ann Surg 2009; 249: $45-57$

36 Moss A, Bourke MJ, Hourigan LF et al. Endoscopic resection for Barrett's high-grade dysplasia and early esophageal adenocarcinoma: an essential staging procedure with long-term therapeutic benefit. Am J Gastroenterol 2010; 105: 1276-1283

37 Pouw RE, Seewald S, Gondrie JJ et al. Stepwise radical endoscopic resection for eradication of Barrett's oesophagus with early neoplasia in a cohort of 169 patients. Gut 2010; 59: 1169 - 1177

38 Shimizu Y, Takahashi M, Yoshida T et al. Endoscopic resection (endoscopic mucosal resection/ endoscopic submucosal dissection) for superficial esophageal squamous cell carcinoma: current status of various techniques. Dig Endosc 2013; 25: 13 -19

39 Neuhaus H, Terheggen G, Rutz EM et al. Endoscopic submucosal dissection plus radiofrequency ablation of neoplastic Barrett's esophagus. Endoscopy 2012; 44: 1105-1113

40 Repici A, Hassan C, Carlino A et al. Endoscopic submucosal dissection in patients with early esophageal squamous cell carcinoma: results from a prospective Western series. Gastrointest Endosc 2010; 71: 715 - 721

41 Peng A, Li Y, Xiao Z et al. Study of clinical treatment of esophageal foreign body-induced esophageal perforation with lethal complications. Eur Arch Otorhinolaryngol 2012; 269: 2027-2036

42 Ukleja A, Afonso BB, Pimentel R et al. Outcome of endoscopic balloon dilation of strictures after laparoscopic gastric bypass. Surg Endosc 2008; 22: $1746-1750$

43 Yoo JH, Shin SJ, Lee KM et al. Risk factors for perforations associated with endoscopic submucosal dissection in gastric lesions: emphasis on perforation type. Surg Endosc 2012; 26: 2456-2464

44 Imagawa A, Okada H, Kawahara Y et al. Endoscopic submucosal dissection for early gastric cancer: results and degrees of technical difficulty as well as success. Endoscopy 2006; 38: 987-990

45 Chung IK, Lee JH, Lee SH et al. Therapeutic outcomes in 1000 cases of endoscopic submucosal dissection for early gastric neoplasms: Korean ESD Study Group multicenter study. Gastrointest Endosc 2009; 69: $1228-1235$

46 Toyokawa T, Inaba T, Omote $S$ et al. Risk factors for perforation and delayed bleeding associated with endoscopic submucosal dissection for early gastric neoplasms: analysis of 1123 lesions. J Gastroenterol Hepatol 2012; 27: $907-912$

47 Ben-David K, Lopes J, Hochwald S et al. Minimally invasive treatment of esophageal perforation using a multidisciplinary treatment algorithm: a case series. Endoscopy 2011; 43: 160-162

48 Kuppusamy MK, Hubka M, Felisky CD et al. Evolving management strategies in esophageal perforation: surgeons using nonoperative techniques to improve outcomes. J Am Coll Surg 2011; 213: 164-171

49 Soreide JA, Viste A. Esophageal perforation: diagnostic work-up and clinical decision-making in the first 24 hours. Scand J Trauma Resusc Emerg Med 2011; 19: 66

50 Bhatia P, Fortin D, Inculet RI et al. Current concepts in the management of esophageal perforations: a twenty-seven year Canadian experience. Ann Thorac Surg 2011; 92: 209-215

51 Qadeer MA, Dumot JA, Vargo JJ et al. Endoscopic clips for closing esophageal perforations: case report and pooled analysis. Gastrointest Endosc 2007; 66: 605-611

52 Daram SR, Tang SJ, Wu $R$ et al. Benchtop testing and comparisons among three types of through-the-scope endoscopic clipping devices. Surg Endosc 2013; 27: 1521 - 1529

53 van Boeckel PG, Sijbring A, Vleggaar FP et al. Systematic review: temporary stent placement for benign rupture or anastomotic leak of the oesophagus. Aliment Pharmacol Ther 2011; 33: 1292 - 1301

54 Johnsson E, Lundell L, Liedman B. Sealing of esophageal perforation or ruptures with expandable metallic stents: a prospective controlled study on treatment efficacy and limitations. Dis Esoph 2005; 18: $262-266$ 
55 van Heel NC, Haringsma J, Spaander MC et al. Short-term esophageal stenting in the management of benign perforations. Am J Gastroenterol 2010; 105: 1515 - 1520

56 Seven G, Irani S, Ross AS et al. Partially versus fully covered self-expanding metal stents for benign and malignant esophageal conditions: a single center experience. Surg Endosc 2013; 27: 2185-2192

57 Ahrens M, Schulte T, Egberts J et al. Drainage of esophageal leakage using endoscopic vacuum therapy: a prospective pilot study. Endoscopy 2010; 42: 693-698

58 Loske G, Schorsch T, Muller C. Intraluminal and intracavitary vacuum therapy for esophageal leakage: a new endoscopic minimally invasive approach. Endoscopy 2011; 43: 540 - 544

59 Vallbohmer D, Holscher AH, Holscher $M$ et al. Options in the management of esophageal perforation: analysis over a 12-year period. Dis Esoph 2010; 23: $185-190$

60 Dumonceau JM, Cremer M, Lalmand B et al. Esophageal fistula sealing: choice of stent, practical management, and cost. Gastrointest Endosc 1999; 49: $70-78$

61 Biancari F, D'Andrea V, Paone R et al. Current treatment and outcome of esophageal perforations in adults: systematic review and meta-analysis of 75 studies. World J Surg 2013; 37: 1051 - 1059

62 Merchea A, Cullinane DC, Sawyer MD et al. Esophagogastroduodenoscopy-associated gastrointestinal perforations: a single-center experience. Surgery 2010; 148: 876 - 880

63 Minami S, Gotoda T, Ono H et al. Complete endoscopic closure of gastric perforation induced by endoscopic resection of early gastric cancer using endoclips can prevent surgery (with video). Gastrointest Endosc 2006; 63: 596-601

64 Han JH, Lee TH, Jung Y et al. Rescue endoscopic band ligation of iatrogenic gastric perforations following failed endoclip closure. World J Gastroenterol 2013; 19: 955 -959

65 Mangiavillano B, Viaggi P, Masci E. Endoscopic closure of acute iatrogenic perforations during diagnostic and therapeutic endoscopy in the gastrointestinal tract using metallic clips: a literature review. J Dig Dis 2010; 11: $12-18$

66 Surace M, Mercky P, Demarquay J-F et al. Endoscopic management of G fistulae with the over-the-scope clip system (with video). Gastrointest Endosc 2011; 74: 1416-1419

67 von Renteln D, Denzer UW, Schachschal G et al. Endoscopic closure of GI fistulae by using an over-the-scope clip (with videos). Gastrointest Endosc 2010; 72: 1289 - 1296

68 Parodi A, Repici A, Pedroni A et al. Endoscopic management of GI perforations with a new over-the-scope clip device (with videos). Gastrointest Endosc 2010; 72: 881 - 886

69 Manta R, Manno M, Bertani $H$ et al. Endoscopic treatment of gastrointestinal fistulas using an over-the-scope clip (OTSC) device: case series from a tertiary referral center. Endoscopy 2011; 43: 545 - 548

70 Kirschniak A, Subotova N, Zieker D et al. The Over-The-Scope Clip (OTSC) for the treatment of gastrointestinal bleeding, perforations, and fistulas. Surg Endosc 2011; 25: 2901 - 2905

71 Baron TH, Song LM, Ross A et al. Use of an over-the-scope clipping device: multicenter retrospective results of the first U.S. experience (with videos). Gastrointest Endosc 2012; 76: 202 - 208

72 Nishiyama $N$, Mori $H$, Kobara $H$ et al. Efficacy and safety of over-thescope clip: including complications after endoscopic submucosal dissection. World J Gastroenterol 2013; 19: 2752 - 2760

73 Martinek J, Ryska O, Tuckova I et al. Comparing over-the-scope clip versus endoloop and clips (KING closure) for access site closure: a randomized experimental study. Surg Endosc 2013; 27: 1203 - 1210

74 Matsuda T, Fujii T, Emura F et al. Complete closure of a large defect after EMR of a lateral spreading colorectal tumor when using a two-channel colonoscope. Gastrointest Endosc 2004; 60: 836-838

75 Ladas SD, Kamberoglou D, Vlachogiannakos J et al. Combined use of metallic endoclips and endoloops using a single-channel scope in closing iatrogenic perforations and fistulas: two case reports and a literature review. Eur J Gastroenterol Hepatol 2014; 26: 119-122

76 Tsunada S, Ogata S, Ohyama T et al. Endoscopic closure of perforations caused by EMR in the stomach by application of metallic clips. Gastrointest Endosc 2003; 57: 948 -951

77 Iwashita T, Lee JG, Nakai Y et al. Successful management of perforation during cystogastrostomy with an esophageal fully covered metallic stent placement. Gastrointest Endosc 2012; 76: 214-215

78 Eroglu A, Turkyilmaz A, Aydin Y et al. Current management of esophageal perforation: 20 years experience. Dis Esoph 2009; 22: 374 - 380
79 Freeman RK, Van Woerkom JM, Vyverberg A et al. Esophageal stent placement for the treatment of spontaneous esophageal perforations. Ann Thorac Surg 2009; 88: 194-198

80 Salminen $P$, Gullichsen $R$, Laine S. Use of self-expandable metal stents for the treatment of esophageal perforations and anastomotic leaks. Surg Endosc 2009; 23: 1526 - 1530

81 Amrani L, Menard C, Berdah $S$ et al. From iatrogenic digestive perforation to complete anastomotic disunion: endoscopic stenting as a new concept of "stent-guided regeneration and re-epithelialization". Gastrointest Endosc 2009; 69: 1282 - 1287

82 Leers JM, Vivaldi C, Schäfer $H$ et al. Endoscopic therapy for esophageal perforation or anastomic leak with a self-expandable metallic stent. Surg Endosc 2009; 10: 2258-2262

83 Kiernan PD, Khandhar SJ, Fortes DL et al. Thoracic esophageal perforations. Am Surg 2010; 76: 1355-1362

84 Schmidt SC, Strauch S, Rosch $T$ et al. Management of esophageal perforations. Surg Endosc 2010; 24: 2809-2813

85 Swinnen J, Eisendrath P, Rigaux J et al. Self-expandable metal stents for the treatment of benign upper GI leaks and perforations. Gastrointest Endosc 2011; 73: 890-899

86 Lazar GJr, Paszt A, Simonka Z et al. A successful strategy for surgical treatment of Boerhaave's syndrome. Surg Endosc 2011; 25: 3613 3619

87 Dai Y, Chopra SS, Kneif S et al. Management of esophageal anastomotic leaks, perforations, and fistulae with self-expanding plastic stents. J Thorac Cardiovasc Surg 2011; 141: 1213-1217

88 D'Cunha J, Rueth NM, Groth SS et al. Esophageal stents for anastomic leaks and perforations. J Thorac Cardiovasc Surg 2011; 142: 39 - 46

89 Lin Y, Jiang G, Liu L et al. Management of thoracic esophageal perforation. World J Surg 2014; 38: 1093-1099

90 Biancari F, Gudbjartsson T, Mennander A et al. Treatment of esophageal perforation in octogenarians: a multicenter study. Dis Esoph Oct 10 [Epub ahead of print] 2013

91 Wilson JL, Louie BE, Farivar AS et al. Fully covered self-expanding metal stents are effective for benign esophagogastric disruptions and strictures. J Gastrointest Surg 2013; 17: 2045-2050

92 Wahed $S$, Dent $B$, Jones $R$ et al. Spectrum of oesophageal perforations and their influence on management. Br J Surg 2014; 101: E156-E162

93 Schweigert M, Beattie R, Solymosi $N$ et al. Endoscopic stent insertion versus primary operative management for spontaneous rupture of the esophagus (Boerhaave syndrome): an international study comparing the outcome. Am Surg 2013; 79: 634-640

94 Sato $H$, Inoue $H$, Ikeda $H$ et al. Clinical experience of esophageal perforation occurring with endoscopic submucosal dissection. Dis Esoph Aug 27 [Epub ahead of print] 2013

95 Heits $N$, Stapel L, Reichert B et al. Endoscopic endoluminal vacuum therapy in esophageal perforation. Ann Thorac Surg 2014; 97: 1029-1035

96 Hadj Amor WB, Bonin EA, Vitton Vet al. Successful endoscopic management of large upper gastrointestinal perforations following EMR using over-the-scope clipping combined with stenting. Endoscopy 2012; 44: E277-E278

97 Biancari F, Saarnio J, Mennander A et al. Outcome of patients with esophageal perforations: a multicenter study. World J Surg 2014; 38: $902-909$

98 Binmoeller KF, Grimm H, Soehendra N. Endoscopic closure of a perforation using metallic clips after snare excision of a gastric leiomyoma. Gastrointest Endosc 1993; 39: 172 - 174

99 Albuquerque $W$, Arantes $V$. Large gastric perforation after endoscopic mucosal resection treated by application of metallic clips (video) Endoscopy 2004; 36: $752-753$

100 Katsinelos P, Beltsis A, Paroutoglou $G$ et al. Endoclipping for gastric perforation after endoscopic polypectomy: an alternative treatment to avoid surgery. Surg Laparosc Endosc Percutan Tech 2004; 14 : $279-281$

101 De Caro G, Pagano N, Malesci A et al. Endoclipping for gastric perforation secondary to second session of EMRC in locally residual early gastric cancer: a case report. Dig Liver Dis 2009; 41: E32 -E34

102 Kim HS, Lee DK, Jeong YS et al. Successful endoscopic management of a perforated gastric dysplastic lesion after endoscopic mucosal resection. Gastrointest Endosc 2000; 51: 613-615

103 Shi $Q$ Chen $T$, Ren $Z$ et al. [Complete closure of large gastric defects after endo- scopic full-thickness resection, using endoloop and metallic clip interrupted suture. Endoscopy 2013; 45: 329-334

104 Zhong Y, Shi Q Yao L et al. [Complete closure of gastric wall defect after endoscopic full-thick resection with metal clips and endoloop 
snare]. Zhonghua Wei Chang Wai Ke Za Zhi (Chinese Journal of Gastrointestinal Surgery 2012; 15: 280-284 [Article in Chinese]

105 Andriulli A, Loperfido S, Napolitano G et al. Incidence rates of postERCP complications: a systematic survey of prospective studies. Am J Gastroenterol 2007; 102: 1781 - 1788

106 Enns R, Eloubeidi MA, Mergener Ket al. ERCP-related perforations: risk factors and management. Endoscopy 2002; 34: 293-298

107 Loperfido S, Angelini G, Benedetti G et al. Major early complications from diagnostic and therapeutic ERCP: a prospective multicenter study. Gastrointest Endosc 1998; 48: 1-10

108 Stapfer M, Selby RR, Stain SC et al. Management of duodenal perforation after endoscopic retrograde cholangiopancreatography and sphincterotomy. Ann Surg 2000; 232: 191 - 198

109 Machado NO. Management of duodenal perforation post-endoscopic retrograde cholangiopancreatography. When and whom to operate and what factors determine the outcome? A review article JOP 2012; 13: $18-25$

110 Howard TJ, Tan T, Lehman GA et al. Classification and management of perforations complicating endoscopic sphincterotomy. Surgery 1999; 126: $658-663$

111 Preetha M, Chung YF, Chan WH et al. Surgical management of endoscopic retrograde cholangiopancreatography-related perforations. ANZ J Surg 2003; 73: $1011-1014$

112 Alfieri S, Rosa F, Cina C et al. Management of duodeno-pancreato-biliary perforations after ERCP: outcomes from an Italian tertiary referral center. Surg Endosc 2013; 27: 2005 - 2012

113 Shami VM, Talreja JP, Mahajan A et al. EUS-guided drainage of bilomas: a new alternative? Gastrointest Endosc 2008; 67: 136-140

114 Chung RS, Sivak MV, Ferguson DR. Surgical decisions in the management of duodenal perforation complicating endoscopic sphincterotomy. Am J Surg 1993; 165: 700 - 703

115 Kayhan B, Akdogan M, Sahin B. ERCP subsequent to retroperitoneal perforation caused by endoscopic sphincterotomy. Gastrointest Endosc 2004; 60: 833-835

116 Knudson K, Raeburn CD, Mcintyre RC et al. Management of duodenal and pancreaticobiliary perforations associated with periampullary endoscopic procedures. Am J Surg 2008; 196: 975-981

117 Rahbour G, Siddiqui MR, Ullah MR et al. A meta-analysis of outcomes following use of somatostatin and its analogues for the management of enterocutaneous fistulas. Ann Surg 2012; 256: 946-954

118 Coughlin S, Roth L, Lurati G et al. Somatostatin analogues for the treatment of enterocutaneous fistulas: a systematic review and meta-analysis. World J Surg 2012; 36: 1016 - 1029

119 Koti RS, Gurusamy KS, Fusai G et al. Meta-analysis of randomized controlled trials on the effectiveness of somatostatin analogues for pancreatic surgery: a Cochrane review. HPB (Oxford) 2010; 12: 155-165

120 Assalia A, Suissa A, Ilivitzki A et al. Validity of clinical criteria in the management of endoscopic retrograde cholangiopancreatography related duodenal perforations. Arch Surg 2007; 142: 1059-1064

121 Avgerinos DV, Llaguna $\mathrm{OH}$, Lo $\mathrm{AY}$ et al. Management of endoscopic retrograde cholangiopancreatography: related duodenal perforations. Surg Endosc 2009; 23: 833-838

122 Dubecz A, Ottmann J, Schweigert M et al. Management of ERCP-related small bowel perforations: the pivotal role of physical investigation. Can J Surg 2012; 55: 99-104

123 Kim BS, Kim IG, Ryu BY et al. Management of endoscopic retrograde cholangiopancreatography-related perforations. J Korean Surg Soc 2011; 81: 195-204

$124 \mathrm{Kim}$ J, Lee SH, Paik WH et al. Clinical outcomes of patients who experienced perforation associated with endoscopic retrograde cholangiopancreatography. Surg Endosc 2012; 26: 3293 -3300

125 Kwon W, Jang J-Y, Ryu JK et al. Proposal of an endoscopic retrograde cholangiopancreatography-related perforation management guideline based on perforation type. J Korean Surg Soc 2012; 83: 218-226

126 Mao Z, Zhu $Q$ Wu $W$ et al. Duodenal perforations after endoscopic retrograde cholangiopancreatography: experience and management. J Laparoendosc Adv Surg Tech A 2008; 18: 691 -695

127 Morgan KA, Fontenot BB, Ruddy JM et al. Endoscopic retrograde cholangiopancreatography gut perforations: when to wait! When to operate! Am Surg 2009; 75: 477-483

128 Wu HM, Dixon E, May GR et al. Management of perforation after endoscopic retrograde cholangiopancreatography (ERCP): a populationbased review. HPB (Oxford) 2006; 8: 393-399
129 Jung JH, Choi KD, Ahn JY et al. Endoscopic submucosal dissection for sessile, nonampullary duodenal adenomas. Endoscopy 2013; 45: $133-135$

130 Hanaoka $N$, Uedo $N$, Ishihara R et al. Clinical features and outcomes of delayed perforation after endoscopic submucosal dissection for early gastric cancer. Endoscopy 2010; 42: 1112-1115

131 Abe $Y$, Inamori $M$, Iida $H$ et al. Clinical characteristics of patients with gastric perforation following endoscopic submucosal resection for gastric cancer. Hepatogastroenterology 2009; 56: 921 - 924

132 Saito Y, Fukuzawa M, Matsuda T et al. Clinical outcome of endoscopic submucosal dissection versus endoscopic mucosal resection of large colorectal tumors as determined by curative resection. Surg Endosc 2010; $24: 343-352$

133 Conio M, De Ceglie A, Filiberti R et al. Cap-assisted EMR of large, sporadic, nonampullary duodenal polyps. Gastrointest Endosc 2012; 76: $1160-1169$

134 Alexander S, Bourke MJ, Williams SJ et al. EMR of large, sessile, sporadic nonampullary duodenal adenomas: technical aspects and longterm outcome (with videos). Gastrointest Endosc 2009; 69: 66 - 73

135 Moschler O, May A, Muller MK et al. Complications in and performance of double-balloon enteroscopy (DBE): results from a large prospective DBE database in Germany. Endoscopy 2011; 43: 484-489

136 Gerson LB, Tokar J, Chiorean $M$ et al. Complications associated with double balloon enteroscopy at nine US centers. Clin Gastroenterol Hepatol 2009; 7: 1177-1182

137 Palmer JS, Marenah K, El Madani F et al. Small bowel perforation following capsule endoscopy: a case report. Ann R Coll Surg Engl 2011; 93: E69-E70

138 Yitzhak A, Bayme M, Perry ZH et al. Small bowel perforation after capsule endoscopy in a patient with occult gastrointestinal bleeding and undiagnosed Crohn's disease. Am Surg 2012; 78: E159-E161

$139 \mathrm{Um} \mathrm{S}$, Poblete H, Zavotsky J. Small bowel perforation caused by an impacted endocapsule. Endoscopy 2008; 40: E122-E123

140 Despott EJ, Gupta A, Burling D et al. Effective dilation of small-bowel strictures by double-balloon enteroscopy in patients with symptomatic Crohn's disease (with video). Gastrointest Endosc 2009; 70: $1030-1036$

141 Espinel J, Pinedo E. Stenosis in gastric bypass: Endoscopic management. World J Gastrointest Endosc 2012; 4: 290-295

142 Donatelli G, Vergeau BM, Dritsas $S$ et al. Closure with an over-thescope clip allows therapeutic ERCP to be safely performed after acute duodenal perforation during diagnostic endoscopic ultrasound. Endoscopy 2013; 45: E392-E393

143 Balmadrid B, Ross A. Severe laceration in a percutaneous endoscopic jejunostomy placement resolved with over-the-scope clips. Gastrointest Endosc 2013; 45: 783-784

144 Palanivelu C, Jategaonkar PA, Rangarajan M et al. Laparoscopic management of a retroperitoneal duodenal perforation following ERCP for periampullary cancer. JSLS 2008; 12: 399-402

145 Ahlawat SK, Haddad N. Repair of an EUS-induced duodenal perforation with endoscopic clips. Acta Gastroenterol Belg 2009; 72: 361 364

146 Honda T, Yamamoto H, Osawa $H$ et al. Endoscopic submucosal dissection for superficial duodenal neoplasms. Dig Endosc 2009; 21: 270274

147 Nakagawa $Y$, Nagai $T$, Soma $W$ et al. Endoscopic closure of a large ERCP-related lateral duodenal perforation by using endoloops and endoclips. Gastrointest Endosc 2010; 72: 216-217

148 Farhat S, Chaussade S, Ponchon T et al. Endoscopic submucosal dissection in a European setting. A multi-institutional report of a technique in development. Endoscopy 2011; 43: 664-670

149 Lee TH, Bang BW, Jeong JI et al. Primary endoscopic approximation suture under cap-assisted endoscopy of an ERCP-induced duodenal perforation. World J Gastroenterol 2010; 16: 2305 -2310

150 Ercan M, Bostanci EB, Dalgic T et al. Surgical outcome of patients with perforation after endoscopic retrograde cholangiopancreatography. J Laparosc Endosc Adv Surg Tech A 2012; 22: 371 - 377

151 Fanning SB, Bourke MJ, Williams SJ et al. Giant laterally spreading tumors of the duodenum: endoscopic resection outcomes, limitations, and caveats. Gastrointest Endosc 2012; 75: 805-812

152 Samarasena JB, Nakai Y, Park DH et al. Endoscopic closure of an iatrogenic duodenal perforation: a novel technique using endoclips, endoloop, and fibrin glue. Endoscopy 2012; 44: E424-E425 
153 Gubler C, Bauerfeind P. Endoscopic closure of iatrogenic gastrointestinal tract perforations with the over-the-scope clip. Digestion 2012; 85: $302-307$

154 Matsumoto S, Miyatani H, Yoshida Y. Endoscopic submucosal dissection for duodenal tumors: a single-center experience. Endoscopy 2013; 45: $136-137$

155 Rabie ME, Mir NH, Al Skaini MS et al. Operative and non-operative management of endoscopic retrograde cholangiopancreatographyassociated duodenal injuries. Ann R Coll Surg Engl 2013; 95: 285 290

156 Teruel C, Garcia XA, Ledo A et al. Small intestine perforation after colonoscopy: rare complication in patients with previous abdominal surgery. Endoscopy 2009; 41: E116

157 Campos JM, Mello FS, Ferraz AA et al. Endoscopic dilation of gastrojejunal anastomosis after gastric bypass. Arq Bras Cir Dig 2012; 25: $283-289$

158 Korman $L Y$, Overholt BF, Box T et al. Perforation during colonoscopy in endoscopic ambulatory surgical centers. Gastrointest Endosc 2003; 58: $554-557$

159 Rabeneck L, Paszat LF, Hilsden RJ et al. Bleeding and perforation after outpatient colonoscopy and their risk factors in usual clinical practice. Gastroenterology 2008; 135: $1899-1906$

160 Saunders BP, Fukumoto M, Halligan $S$ et al. Why is colonoscopy more difficult in women? Gastrointest Endosc 1996; 43: 124-126

161 Navaneethan $U$, Kochhar G, Phull H et al. Severe disease on endoscopy and steroid use increase the risk for bowel perforation during colonoscopy in inflammatory bowel disease patients. J Crohns Colitis 2012; 6: 470-475

162 Rutter MD, Saunders BP, Wilkinson KH et al. Thirty-year analysis of a colonoscopic surveillance program for neoplasia in ulcerative colitis. Gastroenterology 2006; 130: 1030-1038

163 Luning TH, Keemers-Gels ME, Barendregt WB et al. Colonoscopic perforations: a review of 30,366 patients. Surg Endosc 2007; 21: 994 997

164 Putcha RV, Burdick JS. Management of iatrogenic perforation. Gastroenterol Clin North Am 2003; 32: 1289-1309

165 Tribonias G, Konstantinidis K, Theodoropoulou A et al. Rectal perforation caused by colonoscopic retroflexion. Gastrointest Endosc 2010; 71: 662

166 Loffeld RJ, Engel A, Dekkers PE. Incidence and causes of colonoscopic perforations: a single-center case series. Endoscopy 2011; 43: 240 242

167 Stock C, Ihle P, Sieg A et al. Adverse events requiring hospitalization within 30 days after outpatient screening and nonscreening colonoscopies. Gastrointest Endosc 2013; 77: 419 - 429

168 Lee TJ, Rutter MD, Blanks RG et al. Colonoscopy quality measures: experience from the NHS Bowel Cancer Screening Programme. Gut 2012; 61: 1050 - 1057

169 Rabeneck L, Saskin R, Paszat LF. Onset and clinical course of bleeding and perforation after outpatient colonoscopy: a population-based study. Gastrointest Endosc 2011; 73: 520-523

170 Saunders BP, Brown GJ, Lemann M et al. Balloon dilation of ileocolonic strictures in Crohn's disease. Endoscopy 2004; 36: 1001 - 1007

171 Small AJ, Coelho-Prabhu N, Baron TH. Endoscopic placement of self-expandable metal stents for malignant colonic obstruction: long-term outcomes and complication factors. Gastrointest Endosc 2010; 71: $560-572$

172 Suzuki N, Saunders BP, Thomas-Gibson S et al. Colorectal stenting for malignant and benign disease: outcomes in colorectal stenting. Dis Colon Rectum 2004; 47: 1201 - 1207

173 Bowles CJ, Leicester R, Romaya $C$ et al. A prospective study of colonoscopy practice in the UK today: are we adequately prepared for national colorectal cancer screening tomorrow? Gut 2004; 53: 277-283

174 Heldwein W, Dollhopf M, Rosch T et al. The Munich Polypectomy Study (MUPS): prospective analysis of complications and risk factors in 4000 colonic snare polypectomies. Endoscopy 2005; 37: 1116-1122

175 Heresbach D, Kornhauser R, Seyrig JA et al. A national survey of endoscopic mucosal resection for superficial gastrointestinal neoplasia. Endoscopy 2010; 42: 806-813
176 Moss A, Bourke MJ, Williams SJ et al. Endoscopic mucosal resection outcomes and prediction of submucosal cancer from advanced colonic mucosal neoplasia. Gastroenterology 2011; 140: 1909-1918

177 Buchner AM, Guarner-Argente C, Ginsberg GG. Outcomes of EMR of defiant colorectal lesions directed to an endoscopy referral center. Gastrointest Endosc 2012; 76: 255-263

178 Kim ES, Cho KB, Park KS et al. Factors predictive of perforation during endoscopic submucosal dissection for the treatment of colorectal tumors. Endoscopy 2011; 43: $573-578$

179 Toyonaga T, Man-i M, East JE et al. 1,635 Endoscopic submucosal dissection cases in the esophagus, stomach, and colorectum: complication rates and long-term outcomes. Surg Endosc 2013; 27: 1000 1008

180 Tanaka S, Terasaki M, Kanao $H$ et al. Current status and future perspectives of endoscopic submucosal dissection for colorectal tumors. Dig Endosc 2012; 24: $73-79$

181 Repici A, Hassan C, De Paula Pessoa D et al. Efficacy and safety of endoscopic submucosal dissection for colorectal neoplasia: a systematic review. Endoscopy 2012; 44: 137-150

182 Metz AJ, Moss A, McLeod D et al. A blinded comparison of the safety and efficacy of hot biopsy forceps electrocauterization and conventional snare polypectomy for diminutive colonic polypectomy in a porcine model. Gastrointest Endosc 2013; 77: 484 - 490

183 Zissin R, Hertz M, Osadchy A et al. Abdominal CT findings in nontraumatic colorectal perforation. Eur J Radiol 2008; 65: 125-132

184 Iqbal CW, Cullinane DC, Schiller HJ et al. Surgical management and outcomes of 165 colonoscopic perforations from a single institution. Arch Surg 2008; 143: 701 - 706

185 Ignjatovic A, Saunders BP. A clinical case of delayed caecal perforation. Gut 2009; 58: 1170 - 1171

186 La Torre M, Velluti F, Giuliani G et al. Promptness of diagnosis is the main prognostic factor after colonoscopic perforation. Colorectal Dis 2012; 14: E23 - E26

187 Bassan MS, Holt B, Moss A et al. Carbon dioxide insufflation reduces number of postprocedure admissions after endoscopic resection of large colonic lesions: a prospective cohort study. Gastrointest Endosc 2013; 77: 90 - 95

188 Gayer G, Hertz M, Zissin R. Postoperative pneumoperitoneum: prevalence, duration, and possible significance. Semin Ultrasound CT MR 2004; 25: 286-289

189 Raju GS, Ahmed I, Xiao SY et al. Controlled trial of immediate endoluminal closure of colon perforations in a porcine model by use of a novel clip device (with videos). Gastrointest Endosc 2006; 64: 989 997

190 Magdeburg $R$, Collet $P$, Post $S$ et al. Endoclipping of iatrogenic colonic perforation to avoid surgery. Surg Endosc 2008; 22: 1500-1504

191 Byeon JS. Colonic perforation: can we manage it endoscopically? Clin Endosc 2013; 46: 495 - 499

192 Magdeburg $R$, Sold M, Post $S$ et al. Differences in the endoscopic closure of colonic perforation due to diagnostic or therapeutic colonoscopy. Scand J Gastroenterol 2013; 48: 862 - 867

193 Jovanovic I, Zimmermann L, Fry LC et al. Feasibility of endoscopic closure of an iatrogenic colon perforation occurring during colonoscopy. Gastrointest Endosc 2011; 73: 550 - 555

194 Singhal S, Changela K, Papafragkakis $H$ et al. Over the scope clip: technique and expanding clinical applications. J Clin Gastroenterol 2013; 47: $749-756$

195 Weiland T, Fehlker M, Gottwald T et al. Performance of the OTSC System in the endoscopic closure of iatrogenic gastrointestinal perforations: a systematic review. Surg Endosc 2013; 27: 2258 - 2274

196 Han JH, Park S, Youn S. Endoscopic closure of colon perforation with band ligation; salvage technique after endoclip failure. Clin Gastroenterol Hepatol 2011; 9: E54-E55

197 Cho SB, Lee WS, Joo YE et al. Therapeutic options for iatrogenic colon perforation: feasibility of endoscopic clip closure and predictors of the need for early surgery. Surg Endosc 2012; 26: 473-479

198 Pilgrim CH, Nottle PD. Laparoscopic repair of iatrogenic colonic perforation. Surg Laparosc Endosc Percutan Tech 2007; 17: 215 - 217

199 Bleier JI, Moon V, Feingold D et al. Initial repair of iatrogenic colon perforation using laparoscopic methods. Surg Endosc 2008; 22: 646649 